\title{
Time series modeling of air pollution and its association with season and climate variables in istanbul, turkey
}

hazem al-najjar ( $\sim$ hazem_najjar@yahoo.com )

gelisim unversitesi https://orcid.org/0000-0002-6143-2734

Nadia Al-Rousan

Gelisim Universitesi

Ismail A. Elhaty

Gelisim Universitesi

\section{Research}

Keywords: Air quality forecast, feature selection, artificial neural network, NARX, season effect

Posted Date: June 30th, 2020

DOI: https://doi.org/10.21203/rs.3.rs-27820/v4

License: (c) (i) This work is licensed under a Creative Commons Attribution 4.0 International License.

Read Full License 
1 Time series modeling of air pollution and its association with season and climate variables in istanbul, turkey 


\section{Abstract}

12 Air pollution depends on seasons, wind speed, temperature, wind direction and air

13 pressure. The effect of different seasons on air pollution is not fully addressed in the

14 reported works. The current study investigated the impact of season on air pollutants

15 including $\mathrm{SO}_{2}, \mathrm{PM}_{10}, \mathrm{NO}, \mathrm{NO}_{\mathrm{X}}$, and $\mathrm{O}_{3}$ using Nonlinear AutoregRessive network with

16 eXogenous inputs (NARX) method. In the applied methodology, a feature selection

17 was used with each pollutant to find the most important season(s). Afterward, six

18 models are designed based on the feature selection to show the impact of seasons in

19 finding the concentration of pollutants. A case study is conducted on Esenyurt which is

20 one of the most populated and industrialized places in Istanbul to validate the proposed

21 framework. The performance of using all of the designed models with different

22 pollutants showed that using season effect led to improving the performance of

23 predictor and generating high R2 and low error functions.

24 Keywords: Air quality forecast, feature selection, artificial neural network, NARX,

25 season effect.

\section{1. Introduction}

27 Air pollution increases with the increasing of industrialization and urbanization. 
28 Public health and economic development in metropolitan cities are affected by air

29 pollution. Air pollutants' levels and types vary from place to another based on the

30 sources of air pollutants such as cars, power plants, oil refineries, industrial facilities,

31 and factories [1-3]. Air quality is monitored using the most common air pollutants

32 (indicators) including $\mathrm{SO}_{2}, \mathrm{NO}_{2}, \mathrm{CO}_{2}, \mathrm{O}_{3}, \mathrm{NO}, \mathrm{NOx}, \mathrm{PM}_{2.5}$, and $\mathrm{PM}_{10}$ [4]. These

33 indicators can be found in different levels in the ambient air, unfortunately, exceeding

34 the concentration levels of these pollutants will threaten the human health and may

35 cause many serious problems namely long term and short-term problems. One of the

36 most hazardous events produced by air pollutants is the great smog of 1952 in London,

37 which continued for five days and killed 4000. Monitoring and detecting of the

38 concentration of air pollutants can help decision markers to take the right decisions for

39 the current and future plans. An enormous number of researches have been conducted

40 to forecast the pollutants' concentrations and to understand the most suitable way to

41 evaluate the air quality.

42 Cogliani [5] studied the relationship between metrological variables and daily

43 pollution index in three Italian cities using linear multiple partial correlation analysis.

44 The results of forecasting the concentration of pollutants showed high evaluation error 
45 and the methods can be used in the surrounded areas of the observation stations while forecasting the pollutants in places that far away from the station is inapplicable. monthly average concentration of $\mathrm{SO}_{2}, \mathrm{NO}_{2}$ and $\mathrm{PM}_{10}$ by considering the effect of seasons especially winter season. Besides, the study tried to estimate the dataset covered period from January 2001 to December 2005 and was collected from Xigu

51 District's hospitals. The results found a relationship between short-term pollution and

52 low respiratory diseases and found strong relation with winter season on low respiratory

53 diseases. Feng et al.[7] proposed a novel daily $\mathrm{PM}_{2.5}$ forecasting to improve the

54 performance of artificial neural network by using air mass trajectory analysis and

55 wavelet transformation. The dataset is collected from 13 stations from different

56 locations in China including Beijing, Tianjin, and Hebei provinces. The results showed

57 that the new hybrid method can reduce the root mean square error up to $40 \%$.

58 Furthermore, the results indicated that the proposed model is efficient to be applied in

59 different countries.

60 Fortelli et al., (2016) investigated the relationship between local metrological

61 variables and PM10 in Naple, IItaly. Afterward, metrological variables are used to 
63 crises and geopotential heights. The prediction model showed a high correlation

64 between $\mathrm{PM}_{10}$ observations and the predicted values with 0.8 as a correlation coefficient.

65 Alimissis et al. [9] evaluated two interpolation prediction models including Artificial

66 Neural Networks and Multiple Linear Regression, to predict the quality of air in Athens,

67 Greece. The quality of air is majored using five pollutants including Nitrogen dioxide,

68 Nitrogen monoxide, Ozone, Carbon monoxide and Sulphur dioxide. The results showed

69 that artificial neural networks are found in most cases to be significantly superior,

70 especially where the air quality network density is limited.

$71 \mathrm{Yu}$ et al. [10] proposed a fast forecasting method to estimate $\mathrm{PM}_{2.5}$ concentrations

72 in six cities including Baoding, Beijing, Dezhou, Shijiazhuang, Tianjin, and Tangshan,

73 which located in the north of China. The forecasting method is based on source-

74 receptor relationship modeling with backward Lagrangian stochastic particle dispersion

75 model and emission inventory inversion. The forecasting method is built using a dataset

76 collected in 2015, where another dataset collected in 2016 is used for forecasting

77 purposes. The results showed that applying the new techniques can achieve better

78 results and high correlation coefficients compared with non-optimized model. Wang et 
79 al. [11] developed forecasting model to predict an interval PM2.5 concentration using

80 meteorological factors based on multilayer perceptron. To select the most important

81 input variables from the list of variables an interval grey incidence analysis is adopted.

82 In addition, the dataset is collected from three different locations in Beijing, China. The

83 results indicated that the developed model is accurate and stabile than other models in

84 the literatures. Liu et al. [12] developed three-stage hybrid algorithm based on neural

85 network to forecast $\mathrm{PM}_{2.5}$. The dataset is collected from four cities in China, including

86 Beijing, Tianjin, Shijiazhuang, and Tangshan. The results indicated that the accuracy of

87 the proposed model is efficient compared than conventional methods in the field.

88 $\mathrm{Lu}$ [13] investigated the relationship between $\mathrm{PM}_{2.5}$ and $\mathrm{PM}_{10}$ in different locations

89 within Hong Kong province. Based on a relationship between two pollutants, a

90 predictive model is built to estimate the concentration of $\mathrm{PM}_{2.5}$ using $\mathrm{PM}_{10}$ by using

91 three prediction strategies including local, remote and mixed strategies. The results

92 showed that the three used strategies are able to estimate the missing or unmonitored

93 values using the surrounded stations. Zhu et al. [14] proposed two-step-hybrid

94 prediction model to estimate concentrations of $\mathrm{NO}_{2}$ and $\mathrm{SO}_{2}$ pollutants in four cities in

95 Central China region. The model is divided into three steps starting with finding high- 
96 frequency and low-frequency sequences followed by applying Support Vector

97 Regression based on combining the Cuckoo Search algorithm and Grey Wolf Optimizer

98 algorithm and finally, forecasting data of low frequency and high frequency. The results

99 indicated that different hybrid models should be used to efficiently predict high and low

100 frequencies.

101 Catalano et al.[15] studied the relationship between the hourly mean concentration

102 of $\mathrm{NO}_{2}$ and the factors that reflecting the $\mathrm{NO}_{2}$ level (i.e. traffic and weather conditions).

103 Both neural network and Autoregressive Integrated Moving Average with Explanatory

104 (ARIMAX) forecasting methods were used to predict the pollution peaks along with

105 using a combination of these models to forecast the air quality. The results revealed that

106 ARIMAX outperformed neural network in pollution peak forecasting, while neural

107 network could better represent the realistic pollution's concentration association with

108 wind attribute. Integrating both forecasting models could efficiently predict extreme

109 pollution concentrations than using both models separately.

110 Durao et al. [16] forecasted the concentration level of $\mathrm{O}_{3}$ using a combination of

111 metrological and air quality and industrial emissions data for Sines Portuguese region,

112 Portugal. Two forecasting models including Multi-Layer Perceptron (MLP) and 
113 Classification and Regression Trees (CART) were used to predict $\mathrm{O}_{3}$ concentration. The

114 results revealed that MLP successfully predicted $\mathrm{O}_{3}$ concentration within 24 hours

115 ahead.

116 Corani et al. [17] designed multi-label classifier to predict multiple air pollution

117 variables. Bayesian networks were used as a learning technique to predict the level of

$118 \mathrm{PM}_{2.5}$ and ozone in different three studies, and to compare the results with other

119 classifiers. It is found that using multi-label classifier performed better than other

120 independent classifiers.

121 Shi et al. [18] investigated the most metrological variables that have direct or

122 indirect responsibility in serving $\mathrm{PM}_{2.5}$ in Central East China. The results showed

123 increasing in $\mathrm{PM}_{2.5}$ concentration comes as a normal changing in wind direction from

124 south to north, besides increasing in important meteorological factors (i.e., large-scale

125 subsidence, and radiative cooling). Mo et al. [19] investigated the growth of surface

126 ozone concentration and its effect on health. The study tried to develop a new model

127 based on combining different machine learning techniques together as one model. The

128 dataset is collected from four stations in China, then the dataset is divided into training

129 dataset (i.e., 1 May 2014 to 31 May 2017), and testing dataset (i.e., 1 June 2017 to 30 
130 May 2018). The results showed that the proposed model is accurate and stable, besides

131 the model can be used in different locations. Researchers have investigated the

132 capability of predicting the air quality using different prediction models including

133 Artificial intelligent [20-23], Autoregression models [24], and other hybrid models as

134 discussed in [25-27].

135 However, pollutants can make acid rain that has a harmful effect on plants,

136 buildings, monuments, groundwater, soil composition and living organisms inside seas,

137 ponds and rivers. Thus, this study is important, hence, it gives an opportunity for

138 decision-makers to take into account the level of air pollution when developing future

139 plans, especially Turkey is working to increase exports, attract investments and expand

140 construction of factories. Besides, few researchers have focused on finding a

141 relationship between increasing or decreasing pollutants including $\mathrm{SO}_{2}, \mathrm{NO}, \mathrm{NO}_{2}$,

$142 \mathrm{NOX}, \mathrm{O}_{3}$ and $\mathrm{PM}_{10}$ in air and seasons. Besides, researchers have tried to test different

143 combinations between input variables without considering any scientific or

144 mathematical reasons. Therefore, this article comes as important research for both

145 international and national researchers. Our contributions in this research are explained

146 as follow: 
- lack of studies considers the impact of season in understanding the trend of

148 pollutants in air.

149 - lack of studies uses a feature selection with seasons and pollutants to determine

150 the most effective season(s) on each pollutant.

151 - The study presents a new methodology that can be followed to improve 152 pollutants forecasting including $\mathrm{SO}_{2}, \mathrm{NO}, \mathrm{NO}_{2}, \mathrm{NOX}, \mathrm{O}_{3}$ and $\mathrm{PM}_{10}$. Besides, it 153 explains the main behavior between each independent variable and each 154 pollutant to understand the trend of each independent variables on each pollutant.

- The study presents the most effective season(s) on the most important pollutants in Turkey. This can help different researchers to follow the same steps to explain the movement of pollutants in different countries. considering other models. This can save researchers' time and effort. 
164 therefore beneficial to develop a new methodology based on previous studies and

165 feature selection of the most effective season(s) on each pollutant. Afterward, new

166 models will be designed to cover different scenarios. Hence, dataset from one of the

167 most populated sites in Istanbul (Esenyurt) is considered between 2015 and 2019, to

168 validate the used methodology. Furthermore, to compare between different models a

169 determination coefficient with different error functions are used to find the best and

170 most suitable model on each pollutant.

\section{2. Research Methodology}

To build a forecasting model for gases in air, a feature selection method between

173 seasons' variables and each pollutant is used as shown in the following subsections.

\subsection{Data collection and analysis}

The case study was conducted in Esenyurt, one of the most polluted sites in

176 Istanbul, Turkey. The dataset covers 5 years and the total collected hours for all the

177 collected data are 37645 . To build a forecaster model, the dataset is divided into two

178 datasets including training and testing. The training dataset is used to train the

179 forecast model about the historical information of all the gases in ambient air, where

180 the testing dataset is used to check the capability of the trained forecaster to forecast 
181 the future data. The dataset is divided based on the year of the collected information.

182 In which, from 2015 to 2018 is used for training and 2019 is used for testing. To

183 implement the effect of seasons in the collected dataset, four dummy variables for

184 each season are considered. The dummy variable assigns one for starting to ending

185 date and zero otherwise. The statistical description of the training and testing datasets

186 are shown in Tables 1 and 2, respectively. In which, Time, Time, Day, Month, Year,

187 Temperature $\left({ }^{\circ} \mathrm{C}\right)$, Wind direction(Degree), Wind speed $\left(\mathrm{ms}^{-1}\right)$, Relative humidity $(\%)$,

188 Air pressure(mbar) and seasons (based on the results of feature selection) are used as

189 input variables and one of the pollutants including PM10 $\left(\mu \mathrm{gm}^{-3}\right), \mathrm{SO} 2\left(\mu \mathrm{gm}^{-3}\right), \mathrm{NO}$

$190\left(\mu \mathrm{gm}^{-3}\right), \mathrm{NO} 2\left(\mu \mathrm{gm}^{-3}\right), \operatorname{NOX}\left(\mu \mathrm{g} \mathrm{m}^{-3}\right), \mathrm{O} 3\left(\mu \mathrm{g} \mathrm{m}^{-3}\right)$ as output variable.

$191 \quad 2.2$ Design seasons' models based on feature selection

192 After collecting the data from the source, data processing should be conducted.

193 Since, the collected data has no missing value, no outlier values, therefore, sample

194 modelling and design should be the next step to validate the relationship between

195 independent and dependent variables, besides, to find the capability of forecasting air

196 pollution. The study uses six type of air pollutants including PM10, SO2, NO, NO2,

197 NOX and O3, besides Turkey has four seasons, so the total number of models that can 
199 Trying all the combinations is time consuming and a huge number of results will be 200 generated.

201 To minimize the total number of models, a subset attributed evaluator with greedy

202 stepwise search method is used as a feature selection method. The target of using a

203 feature selection is to find the most important seasons(s) that connected with each

204 studied pollutant. The process starts by selecting one of the pollutant gases as a target

205 and all the seasons as input where the rest of metrological variables are used without

206 using feature selection based on the previous studies. The most important season(s) for

207 each pollutant is /are considered. The results of all the models are used to create models.

208 The created models are used to design forecasting models for all the pollutants as shown

209 in Figure 1.

210 In our dataset, a long time hourly (i.e., 30840 hourly readings) data is used to find

211 the most related seasons that connected with each pollutant, then there will be 6806

212 time series samples for forecasting purposes. The most important seasons and the

213 designed models will be discussed in the results section. 
After building models using a feature selection and metrological variables. The

217 NARX forecasting model will be used to forecast different pollutants. The first step in

218 building a forecasting model is to train the NARX model using a training dataset

219 between 2015 and 2018. The NARX will be ran many times until the best model is

220 achieved. The best model that has highest determination coefficient and minimum error

221 are considered for each pollutant. The testing dataset that is not used in training phase

222 between Jan 2019 to Dec 2019 is used to forecast the performance of the trained NARX.

223 The previous two steps are repeated to find the most appropriate weights for NARX

224 models. The best model for each pollutant is used to calculate the performance metrics.

225 For each pollutant, all the generated models are considered and the best model that

226 achieved the best performance metrics are denoted as the best model based on testing

227 dataset (not training dataset). The generated results from NARX and feature selection

228 method are compared together to draw conclusion about the pollutant type and

$229 \operatorname{season}(\mathrm{s})$.

230 Figure 2 shows the NARX network with one output (pollutant) denoted as y, u

231 inputs and $b$ as bias, the process of NARX starts by creating serial parallel architecture 
(opened loop network), then parallel architecture (closed loop network). The target of

233

creating opened and closed network is to improve the forecasting process and to

234 increase the efficiency of the network by using the previous direct data. To forecast the

236 adjust the predicted values.

To sum up all the used methodology in this study a flow chart in Figure 3 is

239 considered.

240

\subsection{Performance analysis}

After building pollutant time series model for each pollutant using a training dataset,

a testing dataset is used to determine the most effective and suitable model for each

pollutant. The results of training and testing dataset using different generated models

244 are evaluated using four metrics including determination coefficient (R2), mean square

calculations of all the performance metrics are presented as follows:

$$
R^{2}=1-\frac{\sum_{i=1}^{N}\left(y_{i}-\widehat{y}_{l}\right)^{2}}{\sum_{i=1}^{N}\left(y_{i}-\bar{y}\right)^{2}}
$$

$$
R M S E=\sqrt{\frac{1}{N} \sum_{i=0}^{N}\left(y_{i}-\widehat{y}_{l}\right)^{2}}
$$




$$
\begin{gathered}
M S E=\frac{1}{N} \sum_{i=0}^{N}\left(y_{i}-\widehat{y}_{l}\right)^{2} \\
M A E=\frac{1}{N} \sum_{i=0}^{N}\left|y_{i}-\widehat{y}_{l}\right|
\end{gathered}
$$

251 The higher $\mathrm{R}^{2}$ and the low error function are considered as a best model, robust and

252 accurate, besides the seasons of the best results are pollutants considered the most

253 effected results that can explain the concentrations of the pollutant.

\section{3. Results, Analysis and Discussion}

\subsection{Study area}

to a metropolitan municipality of the city. Esenyurt is situated on the European part of

261 (Arnavutköy) and Trans-European Motorway (TEM) on the northern region; and 
268 pollutants including $\mathrm{PM}_{10}, \mathrm{SO}_{2}, \mathrm{NO}, \mathrm{NO}_{\mathrm{X}}, \mathrm{NO}_{2}$ and $\mathrm{O}_{3}$, correlation coefficients are

269 shown in Table 3. The most effective date variable on the pollutants is year variable,

270 which shows a decrease in a concentration of all pollutants per year (except $\mathrm{SO}_{2}$ ).

271 Decreasing the concentration of air pollutants (except $\mathrm{SO}_{2}$ ) with time may be attributed

272 to the high percentage of modern cars in Istanbul which emit less pollutants comparing

273 with the old ones. In addition, such decreasing may be attributed to the rules issued by

274 Turkish government to control the emitted pollutants from cars and factories. The

275 growing industry in Turkey, in particular Istanbul, may interpret the increasing

276 concentration of $\mathrm{SO}_{2}$ with time. In general, sulfur dioxide releases from fossil fuel

277 burning power stations, industrial processes such as extracting metal from ore and the

278 burning of fuels with a high sulfur content by locomotives, large ships and non-road

279 equipment [29].

280 In Esenyut, the temperature ranged between $-5^{\circ} \mathrm{C}$ in winter and $38^{\circ} \mathrm{C}$ in summer

281 during the study time period. Temperature has a negative correlation with all pollutants

282 except ozone which showed a positive correlation. These results are almost consistent 
283 with correlation between air pollutants and winter and summer. In this study, the 284 negative correlation could be attributed to the decrease in usage of the domestic heating 285 in summer. In case of ozone, it's mainly formed by a photochemical reaction 286 consequently the more intense the solar radiation (temperature), the more $\mathrm{O}_{3}$ 287 concentrations [30]. Wind speed and direction vary widely in Esenyurt. The average 288 wind speed is $2.225 \mathrm{~m} / \mathrm{s}$ during the study while wind direction at the most is NNE. 289 Wind direction has a positive low correlation with $\mathrm{PM}_{10}, \mathrm{SO}_{2}, \mathrm{NO}, \mathrm{NO}_{2}$ and $\mathrm{NO}_{\mathrm{X}}$, 290 where $\mathrm{O}_{3}$ has negative intermediate relationship with wind direction. Air pollutants in 291 Esenyurt release mainly from local sources such as local industries, traffic and domestic 292 heating. Wind transport air pollutants from Esenyurt to the surrounding places or the 293 inverse. Positive correlation indicates that wind may transport air pollutants towards 294 the monitoring sits. Ozone is unstable molecule and it may be affected by the air 295 movement. In general, it has been found that ozone concentration is higher in the places 296 surrounding the city than inside the city center [31].

297 In general, as the humidity increases, the concentration of air pollutants decreases 298 because of the washing effect [32]. The interference between the relative humidity and 299 other parameters such as temperature explained the variety of the correlation between 
relative humidity and the concentration of air pollutants indicating that it's difficult to

301 analyze meteorological variables in isolation [33]. Air pressure showed a positive

302 correlation with all gases except with $\mathrm{O}_{3}$. The positive results agree with the reported

303 works [20]. The negative effect of pressure on ozone may attributed to the depletion of

304 ozone under pressure.

305

\subsection{Designing forecasting models based on season's variables}

306 Before building a forecasting model and to avoid a lot of combinations between

307 seasons, a feature selection between the season variables and each pollutant gas is

308 considered. Table 4 represents the best effected season on each gas. Based on Table 4

309 and after combining the most effective seasons, 6 models could be generated as

310 represented in Table 5. Models 1 and 6 represent no season effect and all the season

311 effect, respectively. Model 3 represents spring and Autumn, respectively, where Models

3124 and 5 represent summer-winter and Autumn-spring seasons respectively. Therefore,

313 instead of testing 144 models only 6 models are considered in this research. Each gas

314 from the pollution list will use all the models and the best model for each gas are

315 recorded separately as shown in the next section.

316 3.4.Air pollution gases forecasting results 
324 instead of testing 144 models only 6 models are considered in this research. Each gas

325 from the pollution list will use all the models and the best model for each gas are

326 recorded separately as shown in the next section.

\subsection{Air Pollution gases forecasting results}

331 Table 6. The results showed that the best model for training is Model 5 with $\mathrm{R}^{2}$, MSE,

332 MAE and RMSE equal to $0.95,508,10.23$, respectively. While Model 6 showed that

333 the best results for testing are achieved with $\mathrm{R}^{2}$, MSE, MAE and RMSE equal to 0.901, 
334 431, 12, 21, respectively. The results indicate that Autumn and Spring seasons are

335 efficient for training the forecasting model, where for testing, Model 6 showed better

336 performance.

337 To show the fluctuation of errors in the designed models Figure 4 showed that

338 forecasting errors of NO gas in 2019. All models showed higher errors on February and

339 March, where the results of months showed lower errors. The results indicated that

340 using all the seasons variables with metrological variables and time to forecast NO gas

341 is efficient. This indicate that NO gas has a relationship with the seasons, and it change

342 every season.

343 The results of forecasting $\mathrm{NO}_{2}$ gas are shown in Figure 5 and Table 7. NO

344 forecasting results showed that Model 5 and Model 3 are the best models for training

345 and testing respectively. The best $\mathrm{R}^{2}, \mathrm{MSE}, \mathrm{MAE}$ and RMSE are 0.959, 24, 3 and 5,

346 respectively for training, where the best $\mathrm{R}^{2}$, MSE, MAE and RMSE for testing are

$3470.973,37,4$ and 6 , respectively. The forecasting error of $\mathrm{NO}_{2}$ for 2019 is shown in

348 Figure 7, the results of errors showed that February and March have the highest errors

349 using all the models, which indicated that using the metrological variables with Autumn

350 season could achieve the best results for training and testing datasets. The results 
351 revealed that using the season effect can improve the $\mathrm{NO}_{2}$ forecasting.

352

353

For $\mathrm{NO}_{\mathrm{X}}$ training results, Model 5 showed the best performance with $\mathrm{R}^{2}$, MSE,

354 MAE and RMSE are 0.951,1332, 17 and 37, respectively, where for testing results,

355 Model 1 showed the best performance in $\mathrm{R}^{2}$, MSE, MAE and RMSE with values

356 equal to $0.951,1142,16$ and 34, respectively as shown in Table 8. Figure 6 showed the

357 forecasting errors of $\mathrm{NO}_{\mathrm{X}}$ gas using Models 1 to 6 . The forecasting results showed that

358 February and March have the highest errors. The results indicated that no season effect

359 is the best model to describe the behavior of $\mathrm{NO}_{\mathrm{X}}$.

360

361 The forecasting of $\mathrm{O}_{3}$ is shown in Table 9 and Figure 7, the results showed that

362 Model 5 is the best model for training and testing datasets. The results came in line with

363 a correlation analysis in Table 3. The analysis shows that spring and Autumn are the

364 most effective variables on $\mathrm{O}_{3}$ gas. Model 5 shows the lowest errors compared with

365 other models as presented in Figure 9. The results revealed that using a season effect

366 has a great benefit in training all the models, as well as testing dataset.

$367 \quad \mathrm{PM}_{10}$ forecasting results presented in Table 10 and Figure 8, Models 4 and 2 showed

368 best performance for training and testing, respectively. The $\mathrm{PM}_{10}$ results showed that 
spring season has the best results compared with other models. The results indicate that using metrological variables with spring could retrieve the best performance metrics.

$371 \mathrm{SO}_{2}$ forecasting has very bad results compared with $\mathrm{NO}, \mathrm{NO}_{2}, \mathrm{NO}_{\mathrm{X}}, \mathrm{O}_{3}$ and $\mathrm{PM}_{10}$, if

372 Models 2 to 5 are used as shown in Table 11 and Figure 9. Training and testing datasets

373 showed that Model 6 is the best model in improving the performance metrics. The 374 testing performance metrics are $0.888,16,3,4$ for $\mathrm{R}^{2}$, MSE, MAE and RMSE, 375 respectively. The results indicate that using all the seasons could improve the 376 performance of $\mathrm{SO}_{2}$ forecasting. 3.6.Discussion Autumn, spring, summer and winter seasons have strong connections in increasing and decreasing the concentrations of $\mathrm{PM}_{10}, \mathrm{SO}_{2}, \mathrm{NO}, \mathrm{NO}_{\mathrm{X}}, \mathrm{NO}_{2}$ and $\mathrm{O}_{3}$ in air as shown

381 in Table 12. Both training and testing datasets have different behavior in forecasting. $50 \%$ of overall cases showed that Autumn and spring seasons are the dominant model

383 in improving the performance metrics, while, without season effect model showed 384 improvement for $20 \%$ of overall cases. In addition, summer-winter model, spring and 385 autumn models showed 30\% improvement in both datasets. Combining the results of 386 training and testing datasets and eliminating the best results from training dataset. The 
best performance of $\mathrm{PM}_{10}$ is shown with metrological variable and spring season. $\mathrm{SO}_{2}$

and $\mathrm{NO}$ behaved very good with metrological variables with all seasons. $\mathrm{NO}_{2}$ and $\mathrm{O}_{3}$

389 showed a good concentration estimation with spring season and Autumn-spring seasons,

390 respectively, where metrological variables are used as input with the seasons. $\mathrm{NO}_{\mathrm{X}}$ has

391 no improvement with any season and only using metrological variables are affected in

$392 \mathrm{NO}_{\mathrm{X}}$ forecasting. The results of $\mathrm{PM}_{10}$ and $\mathrm{NO}_{2}$ come in line with the feature selection

393 method, where $\mathrm{SO}_{2}, \mathrm{NO}, \mathrm{NO}_{\mathrm{X}}$ and $\mathrm{O}_{3}$ are not in line with feature selection. This

394 indicated that feature selection is appropriate for $\mathrm{PM}_{10}$ and $\mathrm{NO}_{2}$ only.

\section{4. Conclusion}

This work proposes a methodology of using feature selection to find the most

397 effective season(s) on each air pollutant including $\mathrm{PM}_{10}, \mathrm{SO}_{2}, \mathrm{NO}, \mathrm{NO}_{2}, \mathrm{NO}_{\mathrm{x}}$ and $\mathrm{O}_{3}$.

398 Based on the results of feature selection, 6 models are proposed, NARX method is used

399 to build a forecasting model using hourly training dataset between 2015 and 2018,

400 where hourly testing dataset is used for validating the developed models. The dataset is

401 adopted from Esenyurt, Istanbul. The main finding of this study can be summarized as 402 follow: 
- This paper is one of the few studies that considered the effect of season through feature selection method.

- It found that Autumn and spring season are the most effective seasons on the concentration of $\mathrm{NO}_{2}$ and $\mathrm{O} 3$ gases, where spring season and autumn season are effective on $\mathrm{PM}_{10}$ and $\mathrm{NO}_{\mathrm{x}}$, respectively. $\mathrm{SO}_{2}$ and $\mathrm{NO}$ gases, on the other hand,

408 have impact with all seasons. will be used to build more accurate and robust models for different gases in air.

\section{$417 \quad$ Declarations}

\section{Availability of data and materials}

419 All the used data is available publicly in State Institute of Statistics, Republic of 


\section{Competing interests}

422 The authors declare they have no competing interests.

\section{Funding}

424 Not applicable.

\section{Authors' contributions}

426 H. Al-Najjar and N AL-Rousan designed the research model and analysis. The first

427 version is written by H. Al-Najjar and N AL-Rousan. I. Elhaty modified the

428 article, checked and modified the scientific information in the article. All the authors

429 read and approved the final manuscript.

\section{$430 \quad$ References}

431 1. Koop G, McKitrick R, Tole L. Air pollution, economic activity and respiratory

432 illness: evidence from Canadian cities, 1974-1994. Environmental Modelling \&

$433 \quad$ Software. 2019;25(7): 873-85.

434 2. Wyrwa A. An optimization platform for Poland's power sector considering air

435 pollution and health effects. Environmental Modelling \& Software. 2015;74:227- 

(BenMAP-CE): A tool to estimate the health and economic benefits of reducing air pollution. Environmental Modelling \& Software. 2018;104: 118-29. based on Artificial Neural Networks to estimate air pollution health risks. Environmental Modelling \& Software. 2020;123, 104567.

5. Cogliani E. Air pollution forecast in cities by an air pollution index highly correlated with meteorological variables. Atmospheric Environment. 2001;35: 2871-7.

6. Zhu W, Wang J, Zhang, W, Sun D. Short-term effects of air pollution on lower respiratory diseases and forecasting by the group method of data handling. Atmospheric environment 2012;51:29-38. transformation. Atmospheric Environment. 2015;107:118-28. 
8. Fortelli A, Scafetta N, Mazzarella A. Influence of synoptic and local atmospheric patterns on PM10 air pollution levels: a model application to Naples (Italy). Atmospheric environment. 2016;143:218-28.

9. Alimissis A, Philippopoulos K, Tzanis G, Deligiorgi D. Spatial estimation of urban air pollution with the use of artificial neural network models. Atmospheric Environment. 2018;191:205-13. based on footprint modeling and emission optimization. Atmospheric Environment. 2019;219:117013.

11. Wang Z, Chen L, Ding Z, Chen H. An enhanced interval PM2. 5 concentration forecasting model based on BEMD and MLPI with influencing factors. Atmospheric Environment. 2019;117200.

12. Liu H, Chen C. Prediction of outdoor PM2. 5 concentrations based on a three-stage hybrid neural network model. Atmospheric Pollution Research, 2020;11:469-481. 

on data preprocessing and intelligent optimization algorithms (CS and GWO) for NO2 and SO2 forecasting. Atmospheric Pollution Research. 2019;10:1326-35. prediction of air pollution peak episodes generated by urban transport networks. Environmental science \& policy. 2016;60:69-83. up to $24 \mathrm{~h}$ in advance, combining classification trees and MLP models. Atmospheric Pollution Research. 2016;7:961-970.

477 17. Corani G, Scanagatta M. Air pollution prediction via multi-label classification. Environmental modelling \& software. 2016;80:259-264. meteorological mechanisms of transboundary air pollution in a persistent heavy 223: 117239. 

for daily forecasting of ozone mass concentrations based on cycle reservoir with regular jumps neural networks. Atmospheric Environment. 2020, 220, 117072.

20. Dursun S, Kunt F, Taylan O. Modelling sulphur dioxide levels of Konya city using artificial intelligent related to ozone, nitrogen dioxide and meteorological factors. International journal of environmental science and technology. 2015;12: 3915-28.

21. Bai Y, Li Y, Wang X, Xie J, Li C. Air pollutants concentrations forecasting using back propagation neural network based on wavelet decomposition with meteorological conditions. Atmospheric pollution research. 2016;7:557-66.

22. Biancofiore F, Busilacchio M, Verdecchia M, Tomassetti B, Aruffo E, Bianco S, ... Di Carlo P. Recursive neural network model for analysis and forecast of PM10 and PM2.5. Atmospheric Pollution Research 2017;8: 652-9. 
499

500

501

502

503

504

505

506

507

508

509

510

511

512

513

514

515

24. Wang P, Zhang H, Qin Z, Zhang G. A novel hybrid-Garch model based on ARIMA and SVM for PM2. 5 concentrations forecasting. Atmospheric Pollution Research. 2017;8:850-60.

25. Carbajal-Hernández J, Sánchez-Fernández P, Carrasco-Ochoa A, MartínezTrinidad F. Assessment and prediction of air quality using fuzzy logic and autoregressive models. Atmospheric Environment. 2012;60:37-50.

26. Franceschi F, Cobo M, Figueredo M. Discovering relationships and forecasting PM10 and PM2. 5 concentrations in Bogotá, Colombia, using artificial neural networks, principal component analysis, and k-means clustering. Atmospheric Pollution Research. 2018;9:912-22.

27. Yang H, Tao W, Liu Y, Qiu M, Liu J, Jiang K, ... Tao S. The contribution of the Beijing, Tianjin and Hebei region's iron and steel industry to local air pollution in winter. Environmental pollution. 2019;245:1095-1106.

28. State Institute of Statistics, Republic of Turkey Retrieved from http://www.turkstat.gov.tr/Start.do in March 9, 2020

29. Perez P. Prediction of sulfur dioxide concentrations at a site near downtown Santiago, Chile. Atmospheric Environment. 2001;35:4929-35. 
30. Grosjean E, Grosjean D. Formation of ozone in urban air by photochemical oxidation of hydrocarbons: Captive air experiments in Porto Alegre, RS. Journal of the Brazilian Chemical Society 1998;9:131-143.

519

31. Salem A, Soliman A, El-Haty A. Determination of nitrogen dioxide, sulfur dioxide, ozone, and ammonia in ambient air using the passive sampling method associated with ion chromatographic and potentiometric analyses. Air Quality, Atmosphere \& Health. 2009;2:133-145.

32. Kwak Y, Ko J, Lee S, Joh H. Identifying the correlation between rainfall, traffic flow performance and air pollution concentration in Seoul using a path analysis. Transportation research procedia. 2017;25:3552-63. artificial intelligent related to ozone, nitrogen dioxide and meteorological factors. International journal of environmental science and technology. 2015;12: 3915-28. 
Table 1: Statistical description of training data

\begin{tabular}{|c|c|c|c|c|c|c|}
\hline Variable & Mean & Err & $\begin{array}{l}\text { Stan } \\
\text { Dev. }\end{array}$ & Variance & Min & Max \\
\hline Time & 0.482 & .002 & 0.286 & 0.082 & .000 & .958 \\
\hline Day & 15.734 & .050 & 8.827 & 78 & 1.00 & 31 \\
\hline Month & 6.476 & .020 & 3.436 & 12 & 1 & 12 \\
\hline Year & 2016 & 0 & 1.099 & 1 & 2015 & 2018 \\
\hline Temperature & 16.244 & .045 & 7.886 & 62 & -5 & 38 \\
\hline Wind direction & 195.34 & .551 & 96.682 & 9347 & 0 & 360 \\
\hline Wind speed $\left(\mathrm{ms}^{-1}\right)$ & 2.225 & .006 & 1.038 & 1 & 0 & 7 \\
\hline Relative humidity(\%) & 73.645 & .093 & 16.336 & 267 & 0 & 100 \\
\hline Air pressure (mbar) & 1011.94 & 0.06 & 10.64 & 113 & 0 & 1036 \\
\hline Summer & 0.257 & 0.002 & 0.437 & 0 & 0 & 1 \\
\hline Winter & 0.243 & 0.002 & 0.429 & 0 & 0 & 1 \\
\hline Spring & 0.259 & 0.002 & 0.438 & 0 & 0 & 1 \\
\hline Autumn & 0.241 & 0.002 & 0.428 & 0 & 0 & 1 \\
\hline PM10 $\left(\mu \mathrm{gm}^{-3}\right)$ & 81 & 0 & 78 & 6013 & 0 & 985 \\
\hline $\mathrm{SO} 2\left(\mu \mathrm{gm}^{-3}\right)$ & 6 & 0 & 7 & 46 & 0 & 220 \\
\hline $\mathrm{NO}\left(\mu \mathrm{gm}^{-3}\right)$ & 43 & 0 & 71 & 5047 & 0 & 880 \\
\hline NO2 $\left(\mu \mathrm{gm}^{-3}\right)$ & 24 & 0 & 17 & 281 & 0 & 130 \\
\hline $\operatorname{NOX}\left(\mu \mathrm{gm}^{-3}\right)$ & 90 & 1 & 116 & 13390 & 0 & 1338 \\
\hline $\mathrm{O} 3\left(\mu \mathrm{gm}^{-3}\right)$ & 39 & 0 & 26 & 692 & 0 & 866 \\
\hline
\end{tabular}

534

535 Table 2: Statistical description of testing data

\begin{tabular}{lcccccc}
\hline \multicolumn{1}{c}{ Variable } & Mean & Error & S.Dev. & Variance & Min & Max \\
\hline Time & 0.486 & 0.004 & 0.289 & 0.083 & 0 & 1 \\
Day & 15.634 & 0.104 & 8.602 & 73.999 & 1 & 31 \\
Month & 5.834 & 0.038 & 3.148 & 9.911 & 1 & 12 \\
Year & 2019 & 0 & 0.000 & 0.000 & 2019 & 2019 \\
Temperature $\left({ }^{\circ} \mathrm{C}\right)$ & 17.509 & 0.094 & 7.756 & 60.152 & 0.12 & 34 \\
Wind direction $($ Degree) & 192.874 & 0.921 & 75.970 & 5771.462 & 34.86 & 350 \\
Wind speed $\left(\mathrm{ms}^{-1}\right)$ & 2.110 & 0.012 & 1.021 & 1.043 & 0.06 & 6 \\
Relative humidity(\%) & 73.382 & 0.198 & 16.304 & 265.829 & 16.08 & 100 \\
Air pressure (mbar) & 1010.477 & 0.068 & 5.573 & 31.060 & 993.39 & 1028 \\
\hline
\end{tabular}




\begin{tabular}{lcccccc}
\hline Summer & 0.273 & 0.005 & 0.446 & 0.199 & 0 & 1 \\
Winter & 0.201 & 0.005 & 0.401 & 0.161 & 0 & 1 \\
Spring & 0.305 & 0.006 & 0.460 & 0.212 & 0 & 1 \\
Autumn & 0.221 & 0.005 & 0.415 & 0.172 & 0 & 1 \\
\hline $\mathrm{PM}_{10}\left(\mu \mathrm{gm}^{-3}\right)$ & 60 & 1 & 42 & 1801 & 6 & 509 \\
$\mathrm{SO}_{2}\left(\mu \mathrm{gm}^{-3}\right)$ & 10 & 0 & 7 & 51 & 0 & 100 \\
$\mathrm{NO}^{-3}\left(\mu \mathrm{gm}^{-3}\right)$ & 20 & 1 & 45 & 2033 & 0 & 696 \\
$\mathrm{NO}_{2}\left(\mu \mathrm{gm}^{-3}\right)$ & 29 & 0 & 18 & 332 & 2 & 152 \\
$\mathrm{NO}_{\mathrm{X}}\left(\mu \mathrm{gm}^{-3}\right)$ & 61 & 1 & 82 & 6760 & 2 & 1219 \\
$\mathrm{O}_{3}\left(\mu \mathrm{gm}^{-3}\right)$ & 24 & 0 & 17 & 292 & 0 & 97 \\
\hline
\end{tabular}

536

Table 3: Correlation coefficient between input and output variables

\begin{tabular}{lcccccc}
\hline Variable & PM10 & SO2 & NO & NO2 & NOX & O3 \\
\hline Time & 0.110 & 0.082 & -0.003 & 0.159 & 0.021 & 0.092 \\
Day & -0.028 & -0.021 & -0.007 & -0.004 & -0.005 & 0.004 \\
Month & -0.011 & -0.096 & 0.048 & -0.037 & 0.049 & -0.043 \\
Year & -0.226 & 0.190 & -0.075 & -0.020 & -0.067 & -0.050 \\
Temperature & -0.055 & -0.136 & -0.254 & -0.109 & -0.245 & 0.380 \\
Wind direction & 0.057 & 0.045 & 0.197 & 0.094 & 0.198 & -0.212 \\
Wind speed & -0.225 & -0.061 & -0.355 & -0.416 & -0.395 & 0.441 \\
Relative humidity & -0.071 & -0.115 & 0.149 & 0.018 & 0.142 & -0.395 \\
Air pressure & 0.074 & 0.025 & 0.130 & 0.051 & 0.130 & -0.136 \\
Summer & -0.102 & -0.117 & -0.205 & -0.134 & -0.207 & 0.255 \\
Winter & -0.005 & 0.245 & 0.143 & 0.041 & 0.136 & -0.187 \\
Spring & 0.116 & -0.039 & -0.024 & 0.047 & -0.027 & 0.036 \\
Autumn & -0.011 & -0.083 & 0.093 & 0.048 & 0.106 & -0.114 \\
\hline
\end{tabular}

538

539

540

541

542

543

544

545 
546 Table 4: The most effect season(s) on each gas using subsets attribute evaluator with 547 greed stepwise search method.

\begin{tabular}{cc}
\hline Gas & Most Effected Season \\
\hline $\mathrm{PM}_{10}$ & Spring \\
$\mathrm{SO}_{2}$ & Summer, winter \\
$\mathrm{NO}$ & Summer, winter \\
$\mathrm{NO}_{2}$ & Autumn \\
$\mathrm{NOX}$ & Autumn, Spring \\
$\mathrm{O}_{3}$ & Spring, Autumn, Spring, Winter \\
\hline
\end{tabular}

548

549 Table 5: Model design and description of each model.

\begin{tabular}{cl}
\hline Model No. & \multicolumn{1}{c}{ Description } \\
\hline 1 & Without Season effect \\
2 & Spring \\
3 & Autumn \\
4 & Summer, Winter \\
5 & Autumn, Spring \\
6 & Spring, Autumn, Spring, Winter \\
\hline
\end{tabular}

550

551 Table 6: The performance of NO gas prediction using training and testing datasets

\begin{tabular}{ccccccc}
\hline Dataset & Model & Gas & R2 & MSE & MAE & RMSE \\
\hline Training & 1 & NO & 0.944 & 559.89 & 10.86 & 23.66 \\
& 2 & NO & 0.946 & 540.50 & 10.99 & 23.25 \\
& 3 & NO & 0.943 & 571.06 & 10.82 & 23.90 \\
& 4 & NO & 0.944 & 551.49 & 10.81 & 23.48 \\
& 5 & NO & 0.950 & 508.47 & 9.84 & 22.55 \\
& 6 & NO & 0.949 & 507.04 & 10.62 & 22.52 \\
\hline \multirow{7}{*}{ Testing } & 1 & NO & 0.894 & 430.62 & 10.18 & 20.75 \\
& 2 & NO & 0.864 & 533.95 & 11.18 & 23.11 \\
& 3 & NO & 0.877 & 565.95 & 14.14 & 23.79 \\
& 4 & NO & 0.890 & 456.10 & 11.22 & 21.36 \\
& 5 & NO & 0.867 & 540.75 & 10.83 & 23.25 \\
& 6 & NO & 0.901 & 431.54 & 11.59 & 20.77 \\
\hline
\end{tabular}


553 Table 7: The performance of $\mathrm{NO}_{2}$ gas prediction using training and testing datasets

\begin{tabular}{ccccccc}
\hline Dataset & Model & Gas & $\mathrm{R}^{2}$ & MSE & MAE & RMSE \\
\hline Training & 1 & $\mathrm{NO}_{2}$ & 0.945 & 30.81 & 3.73 & 5.55 \\
& 2 & $\mathrm{NO}_{2}$ & 0.910 & 48.93 & 4.79 & 7.00 \\
& 3 & $\mathrm{NO}_{2}$ & 0.958 & 24.29 & 3.47 & 4.93 \\
& 4 & $\mathrm{NO}_{2}$ & 0.949 & 29.15 & 3.74 & 5.40 \\
& 5 & $\mathrm{NO}_{2}$ & 0.959 & 24.20 & 3.48 & 4.92 \\
& 6 & $\mathrm{NO}_{2}$ & 0.938 & 34.57 & 4.01 & 5.88 \\
\hline \multirow{7}{*}{ Testing } & 1 & $\mathrm{NO}_{2}$ & 0.961 & 56.87 & 5.35 & 7.54 \\
& 2 & $\mathrm{NO}_{2}$ & 0.960 & 40.44 & 4.14 & 6.36 \\
& 3 & $\mathrm{NO}_{2}$ & 0.973 & 36.81 & 4.28 & 6.07 \\
& 4 & $\mathrm{NO}_{2}$ & 0.953 & 44.20 & 4.32 & 6.65 \\
& 5 & $\mathrm{NO}_{2}$ & 0.971 & 49.07 & 4.97 & 7.01 \\
& 6 & $\mathrm{NO}_{2}$ & 0.950 & 49.06 & 4.48 & 7.00 \\
\hline
\end{tabular}

554

555 Table 8: The performance of $\mathrm{NO}_{\mathrm{X}}$ gas prediction using training and testing datasets

\begin{tabular}{ccccccc}
\hline Dataset & Model & Gas & $\mathrm{R}^{2}$ & MSE & MAE & RMSE \\
\hline Training & 1 & NOx & 0.946 & 1419.45 & 17.64 & 37.68 \\
& 2 & NOx & 0.944 & 1478.56 & 18.86 & 38.45 \\
& 3 & NOx & 0.942 & 1526.45 & 18.14 & 39.07 \\
& 4 & NOx & 0.944 & 1474.48 & 18.21 & 38.40 \\
& 5 & NOx & 0.951 & 1332.15 & 16.68 & 36.50 \\
& 6 & NOx & 0.949 & 1357.84 & 17.99 & 36.85 \\
\hline Testing & 1 & NOx & 0.915 & 1141.55 & 15.53 & 33.79 \\
& 2 & NOx & 0.892 & 1463.17 & 18.60 & 38.25 \\
& 3 & NOx & 0.902 & 1403.59 & 20.39 & 37.46 \\
& 4 & NOx & 0.907 & 1277.21 & 18.33 & 35.74 \\
& 5 & NOx & 0.892 & 1471.76 & 17.43 & 38.36 \\
& 6 & NOx & 0.913 & 1241.92 & 19.37 & 35.24 \\
\hline
\end{tabular}

556

557

558 
$559 \quad$ Table 9: The performance of $\mathrm{O}_{3}$ gas prediction using training and testing datasets

\begin{tabular}{ccccccc}
\hline Dataset & Model & Gas & R2 & MSE & MAE & RMSE \\
\hline Training & 1 & $\mathrm{O}_{3}$ & 0.947 & 72.72 & 4.74 & 8.53 \\
& 2 & $\mathrm{O}_{3}$ & 0.954 & 64.54 & 4.91 & 8.03 \\
& 3 & $\mathrm{O}_{3}$ & 0.959 & 57.85 & 4.91 & 7.61 \\
& 4 & $\mathrm{O}_{3}$ & 0.959 & 56.64 & 4.62 & 7.53 \\
& 5 & $\mathrm{O}_{3}$ & 0.965 & 50.86 & 4.50 & 7.13 \\
& 6 & $\mathrm{O}_{3}$ & 0.949 & 70.56 & 5.20 & 8.40 \\
\hline \multirow{6}{*}{ Testing } & 1 & $\mathrm{O}_{3}$ & 0.946 & 65.04 & 6.32 & 8.06 \\
& 2 & $\mathrm{O}_{3}$ & 0.928 & 69.67 & 6.25 & 8.35 \\
& 3 & $\mathrm{O}_{3}$ & 0.948 & 57.66 & 6.30 & 7.59 \\
& 4 & $\mathrm{O}_{3}$ & 0.959 & 53.79 & 6.15 & 7.33 \\
& 5 & $\mathrm{O}_{3}$ & 0.963 & 47.69 & 5.75 & 6.91 \\
& 6 & $\mathrm{O}_{3}$ & 0.941 & 42.82 & 4.99 & 6.54 \\
\hline
\end{tabular}

560

561 Table 10: The performance of $\mathrm{PM}_{10}$ gas prediction using training and testing datasets

\begin{tabular}{ccccccc}
\hline Dataset & Model & Gas & R2 & MSE & MAE & RMSE \\
\hline Training & 1 & $\mathrm{PM}_{10}$ & 0.943 & 669.14 & 13.09 & 25.87 \\
& 2 & $\mathrm{PM}_{10}$ & 0.950 & 590.93 & 12.66 & 24.31 \\
& 3 & $\mathrm{PM}_{10}$ & 0.947 & 631.69 & 12.81 & 25.13 \\
& 4 & $\mathrm{PM}_{10}$ & 0.952 & 579.37 & 14.06 & 24.07 \\
& 5 & $\mathrm{PM}_{10}$ & 0.944 & 664.06 & 13.17 & 25.77 \\
& 6 & $\mathrm{PM}_{10}$ & 0.947 & 640.62 & 12.91 & 25.31 \\
\hline \multirow{6}{*}{ Testing } & 1 & $\mathrm{PM}_{10}$ & 0.925 & 314.89 & 9.84 & 17.75 \\
& 2 & $\mathrm{PM}_{10}$ & 0.927 & 256.98 & 8.79 & 16.03 \\
& 3 & $\mathrm{PM}_{10}$ & 0.911 & 309.40 & 9.48 & 17.59 \\
& 4 & $\mathrm{PM}_{10}$ & 0.919 & 291.38 & 10.18 & 17.07 \\
& 5 & $\mathrm{PM}_{10}$ & 0.906 & 342.02 & 9.63 & 18.49 \\
& 6 & $\mathrm{PM}_{10}$ & 0.915 & 303.95 & 9.05 & 17.43 \\
\hline
\end{tabular}

562

563

564 
565 Table 11: The performance of $\mathrm{SO}_{2}$ gas prediction using training and testing datasets

\begin{tabular}{ccccccc}
\hline Dataset & Model & $\mathrm{Gas}$ & $\mathrm{R} 2$ & MSE & MAE & RMSE \\
\hline Training & 1 & $\mathrm{SO}_{2}$ & 0.811 & 16.01 & 2.57 & 4.00 \\
& 2 & $\mathrm{SO}_{2}$ & 0.683 & 24.80 & 2.95 & 4.98 \\
& 3 & $\mathrm{SO}_{2}$ & 0.330 & 41.07 & 3.91 & 6.41 \\
& 4 & $\mathrm{SO}_{2}$ & 0.550 & 32.20 & 3.44 & 5.67 \\
& 5 & $\mathrm{SO}_{2}$ & 0.727 & 22.08 & 2.73 & 4.70 \\
& 6 & $\mathrm{SO}_{2}$ & 0.803 & 16.59 & 2.52 & 4.07 \\
\hline \multirow{7}{*}{ Testing } & 1 & $\mathrm{SO}_{2}$ & 0.824 & 34.60 & 4.37 & 5.88 \\
& 2 & $\mathrm{SO}_{2}$ & 0.039 & 69.57 & 5.52 & 8.34 \\
& 3 & $\mathrm{SO}_{2}$ & 0.338 & 48.53 & 4.62 & 6.97 \\
& 4 & $\mathrm{SO}_{2}$ & 0.462 & 44.23 & 4.36 & 6.65 \\
& 5 & $\mathrm{SO}_{2}$ & 0.756 & 28.08 & 3.46 & 5.30 \\
& 6 & $\mathrm{SO}_{2}$ & 0.888 & 16.47 & 2.74 & 4.06 \\
\hline
\end{tabular}

566

567 Table 12: The best model for each gas using training and testing datasets.

\begin{tabular}{ccccc}
\hline Dataset & Gas & $\mathbf{R}^{\mathbf{2}}$ & Best Model & Description \\
\hline Training & $\mathrm{PM}_{10}$ & 0.952 & 4 & Autumn Spring \\
& $\mathrm{SO}_{2}$ & 0.811 & 1 & Without Season effect \\
& $\mathrm{NO}$ & 0.950 & 5 & Autumn Spring \\
& $\mathrm{NO}_{2}$ & 0.959 & 5 & Autumn Spring \\
& $\mathrm{NO}_{x}$ & 0.951 & 5 & Autumn Spring \\
& $\mathrm{O}_{3}$ & 0.965 & 5 & Autumn Spring \\
\hline Testing & $\mathrm{PM}_{10}$ & 0.927 & 2 & Spring \\
& $\mathrm{SO}_{2}$ & 0.888 & 6 & All seasons \\
& $\mathrm{NO}^{2}$ & 0.901 & 6 & All seasons \\
& $\mathrm{NO}_{2}$ & 0.973 & 3 & Autumn \\
& $\mathrm{NO}_{\mathrm{X}}$ & 0.915 & 1 & Without Season effect \\
& $\mathrm{O}_{3}$ & 0.963 & 5 & Autumn Spring \\
\hline
\end{tabular}

568 


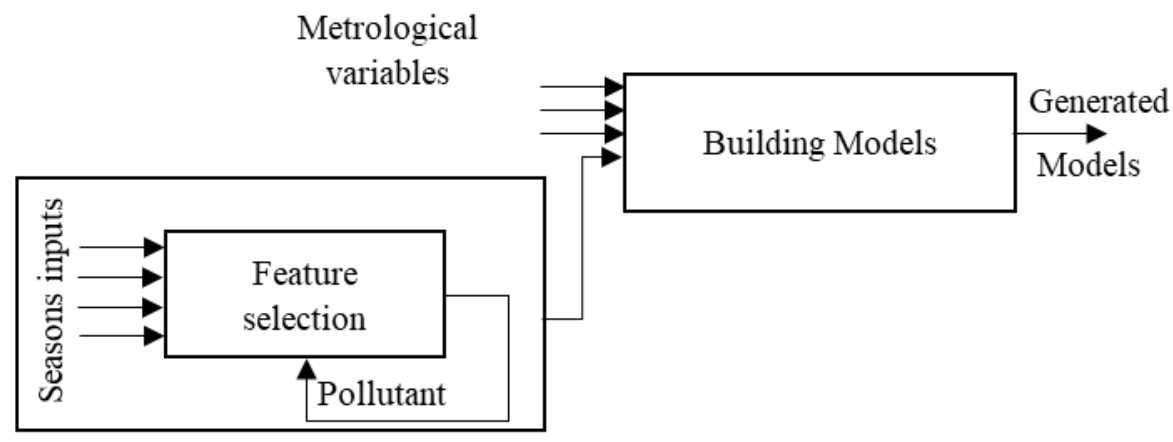

570 Figure 1: The created models' methodology.

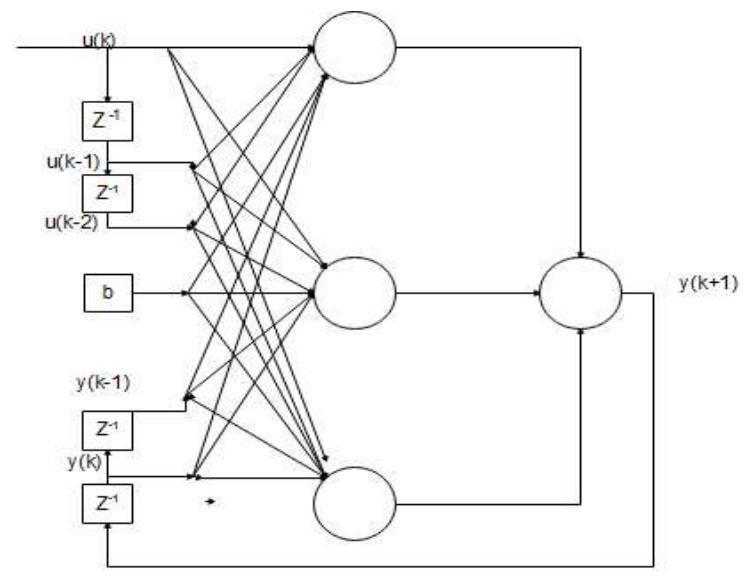

Figure 2: NARX model with tapped delay line at input.

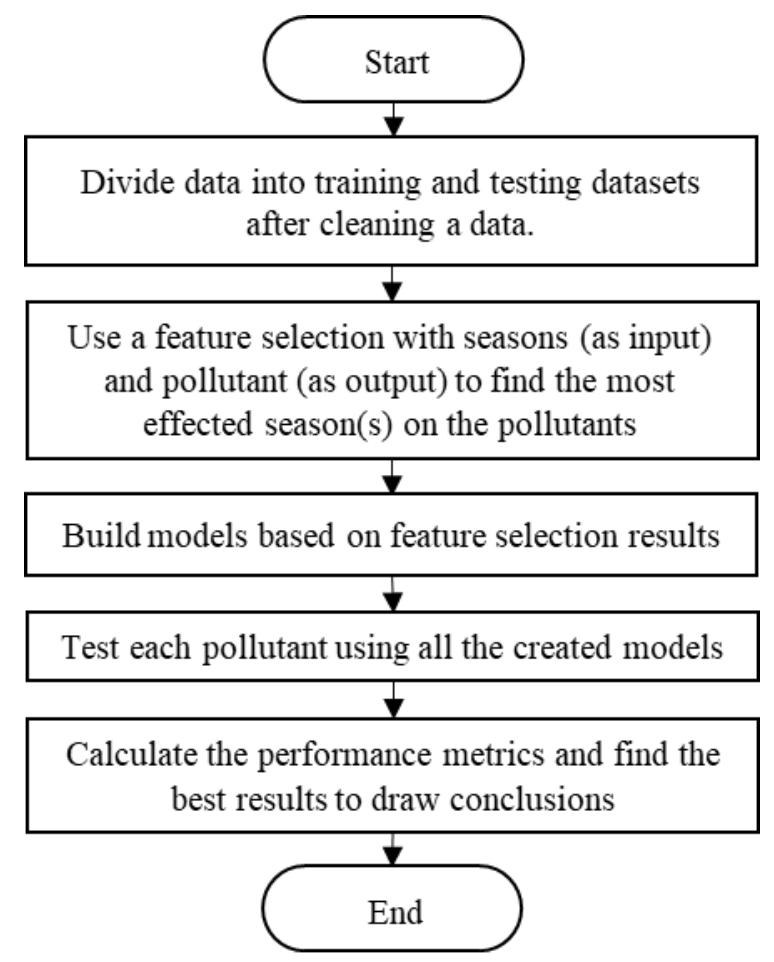

Figure 3: The used methodology to build models. 

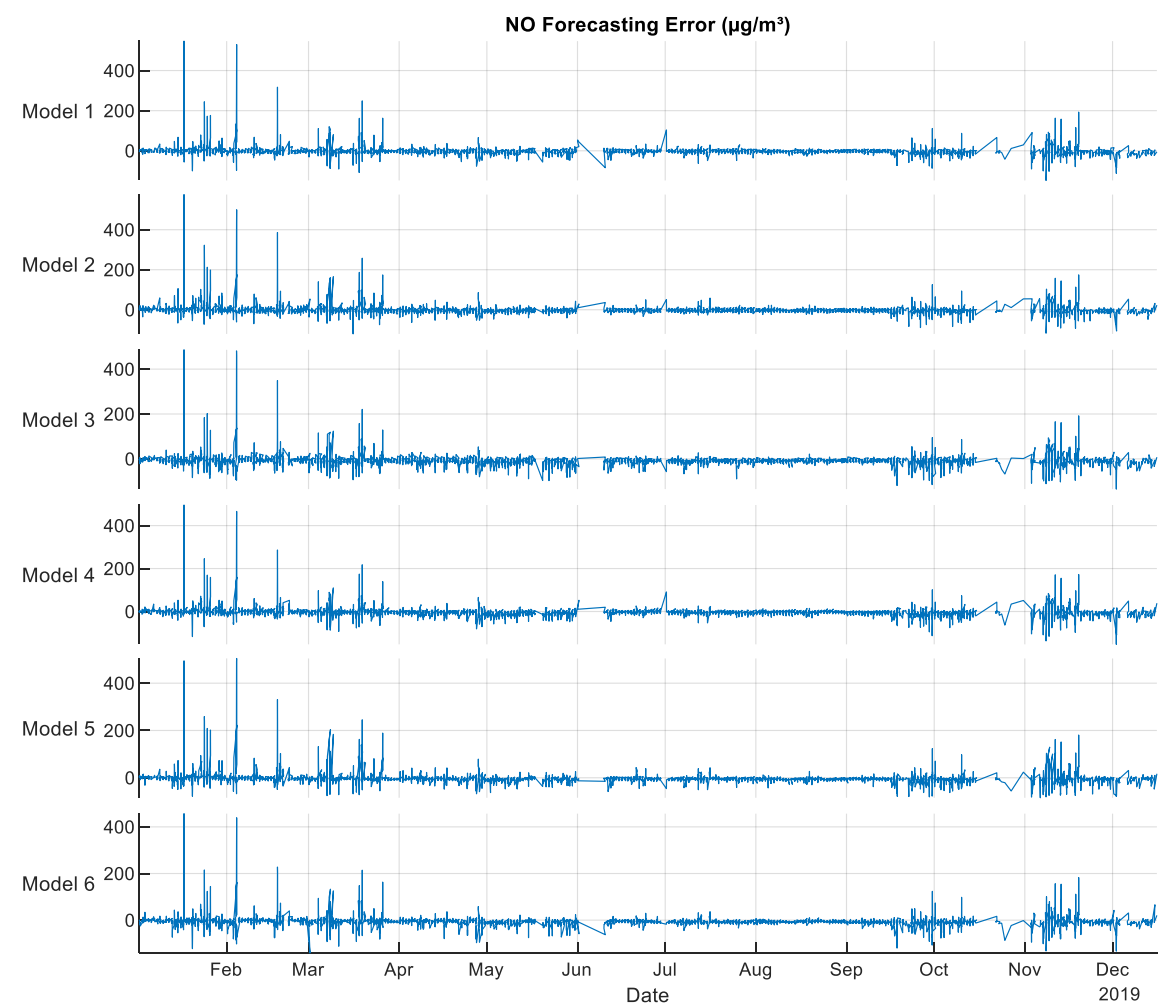

575

576 Figure 4: NO error $\left(\mu \mathrm{gm}^{-3}\right)$ forecasting for 2019 using NARX. 


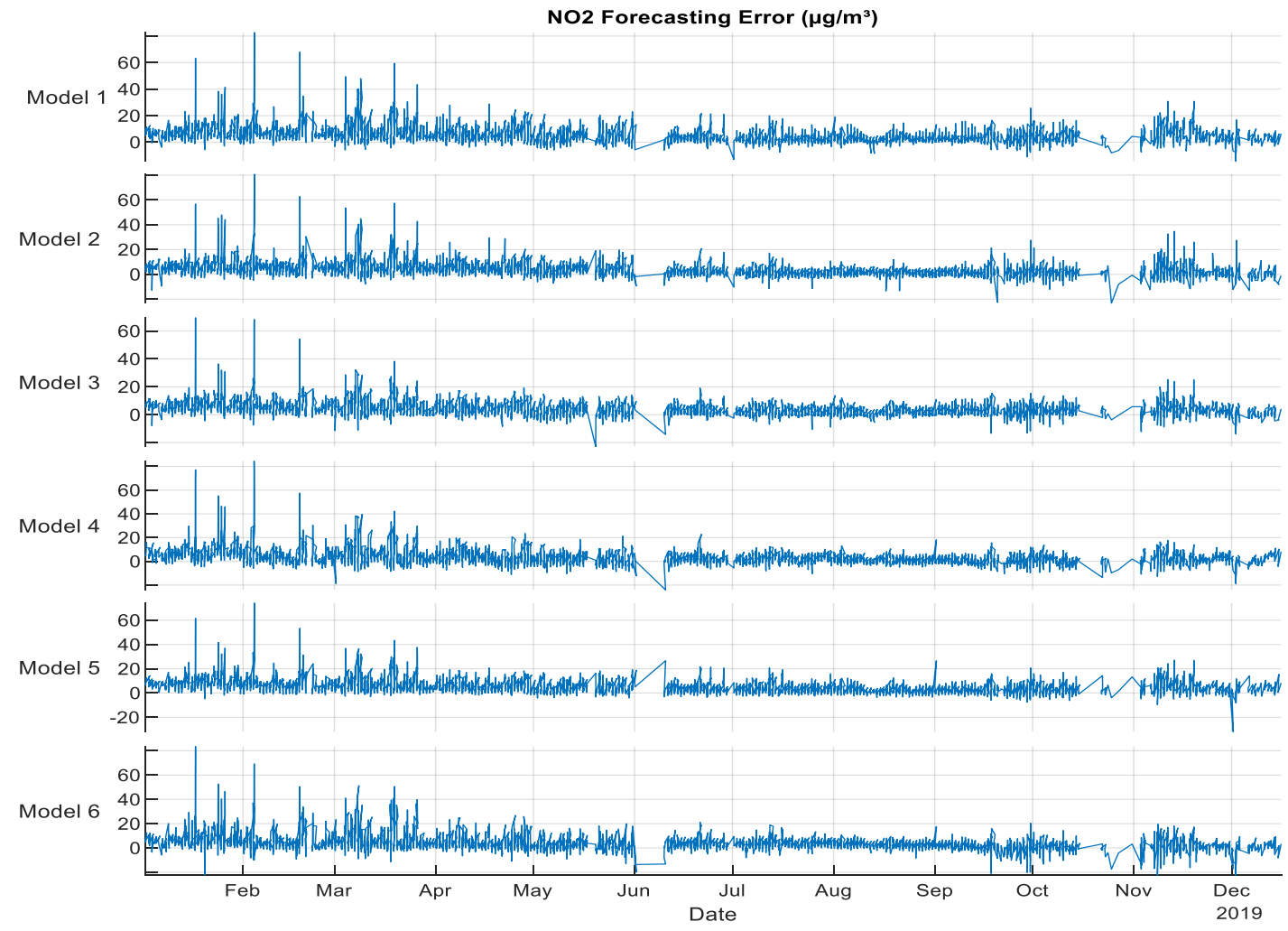

$578 \quad$ Figure 5: $\mathrm{NO}_{2}$ error $\left(\mu \mathrm{g} / \mathrm{m}^{3}\right)$ forecasting for 2019 using NARX. 


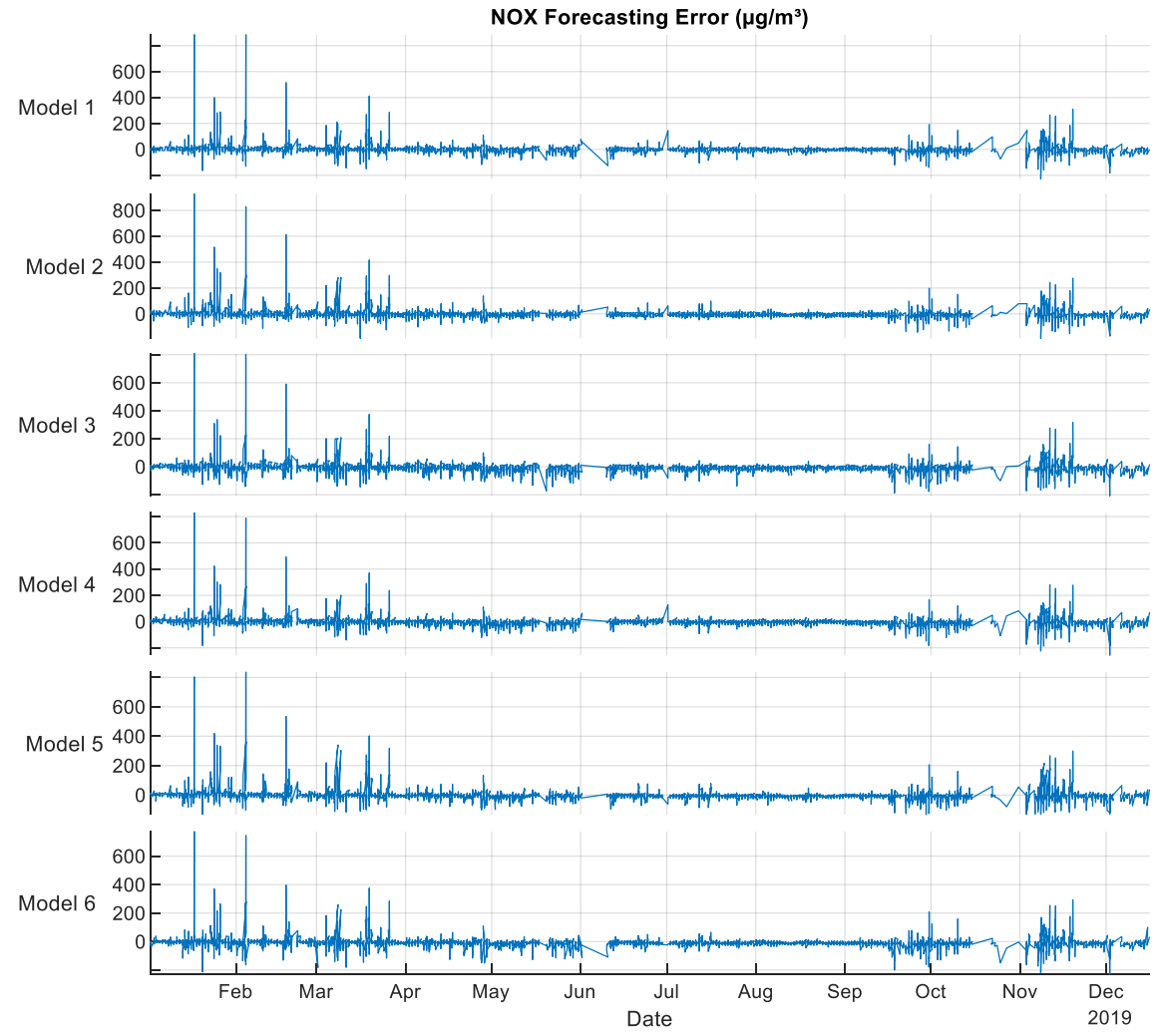

579

Figure 6: $\mathrm{NO}$ X error $\left(\mu \mathrm{g} / \mathrm{m}^{3}\right)$ forecasting errors for 2019 using NARX. 


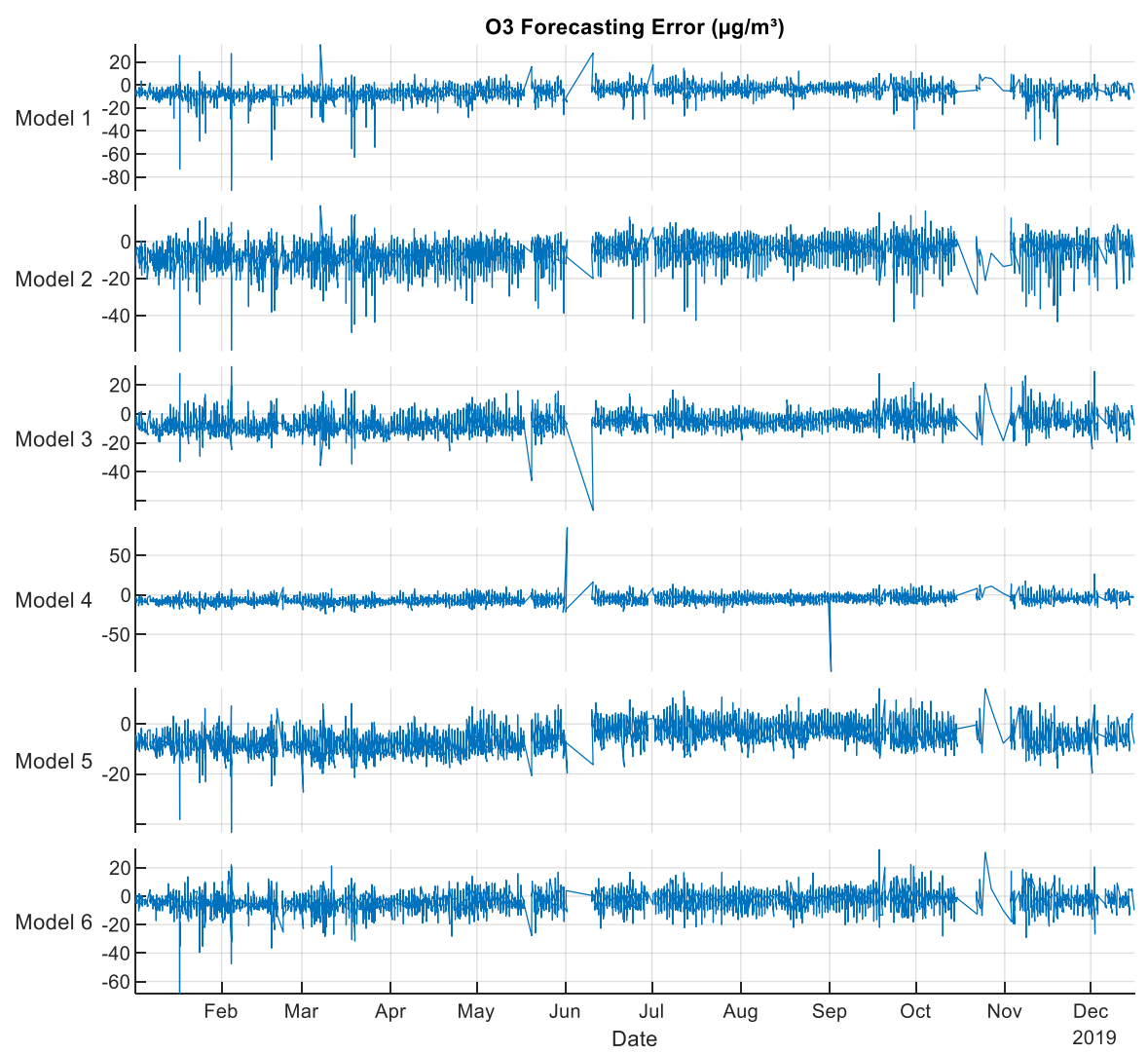

581

582 Figure 7: $\mathrm{O}_{3}$ error $\left(\mu \mathrm{g} / \mathrm{m}^{3}\right)$ forecasting errors for 2019 using NARX. 


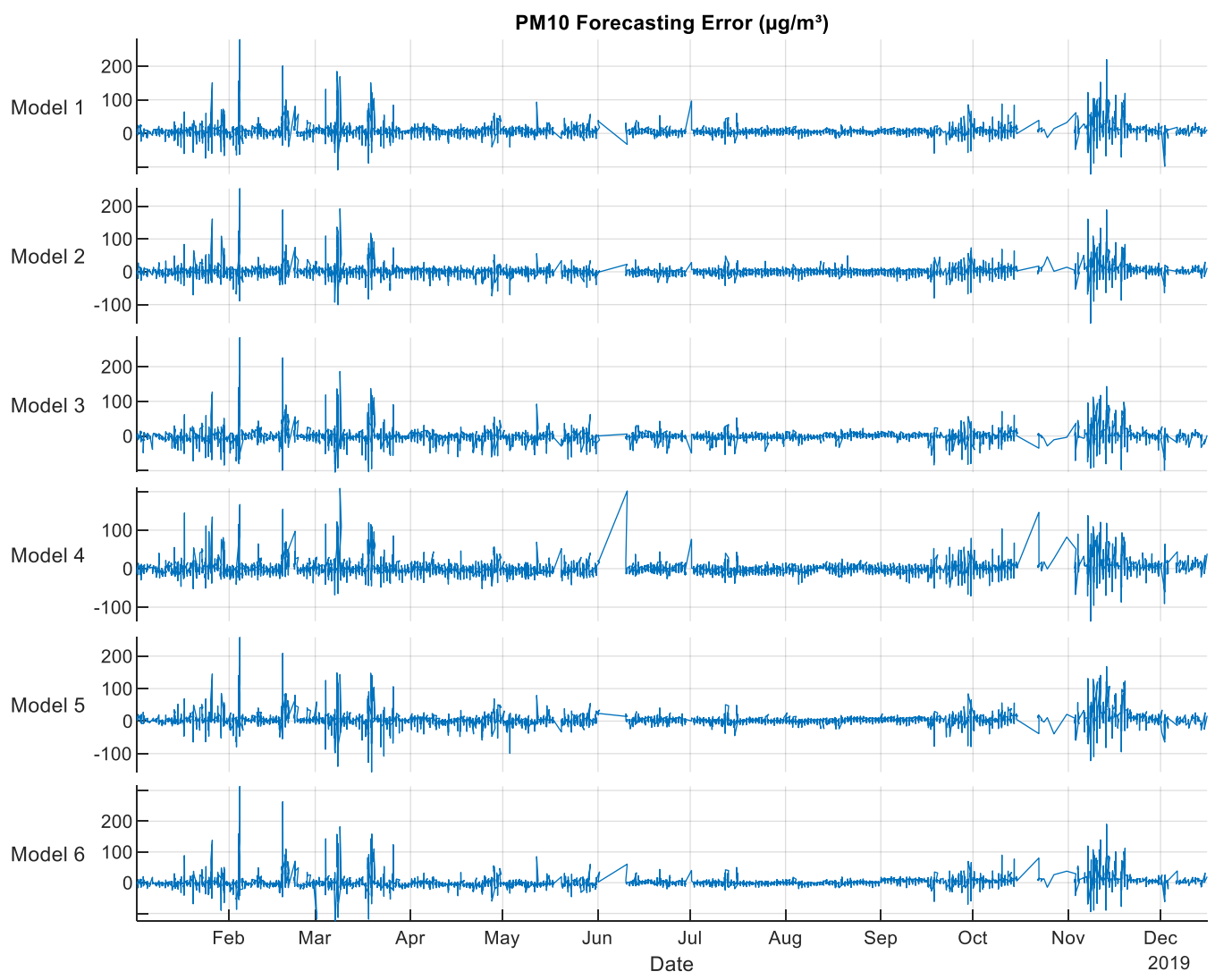

583

584 Figure 8: $\mathrm{PM}_{10}$ error $\left(\mu \mathrm{g} / \mathrm{m}^{3}\right)$ forecasting errors for 2019 using NARX.

585 

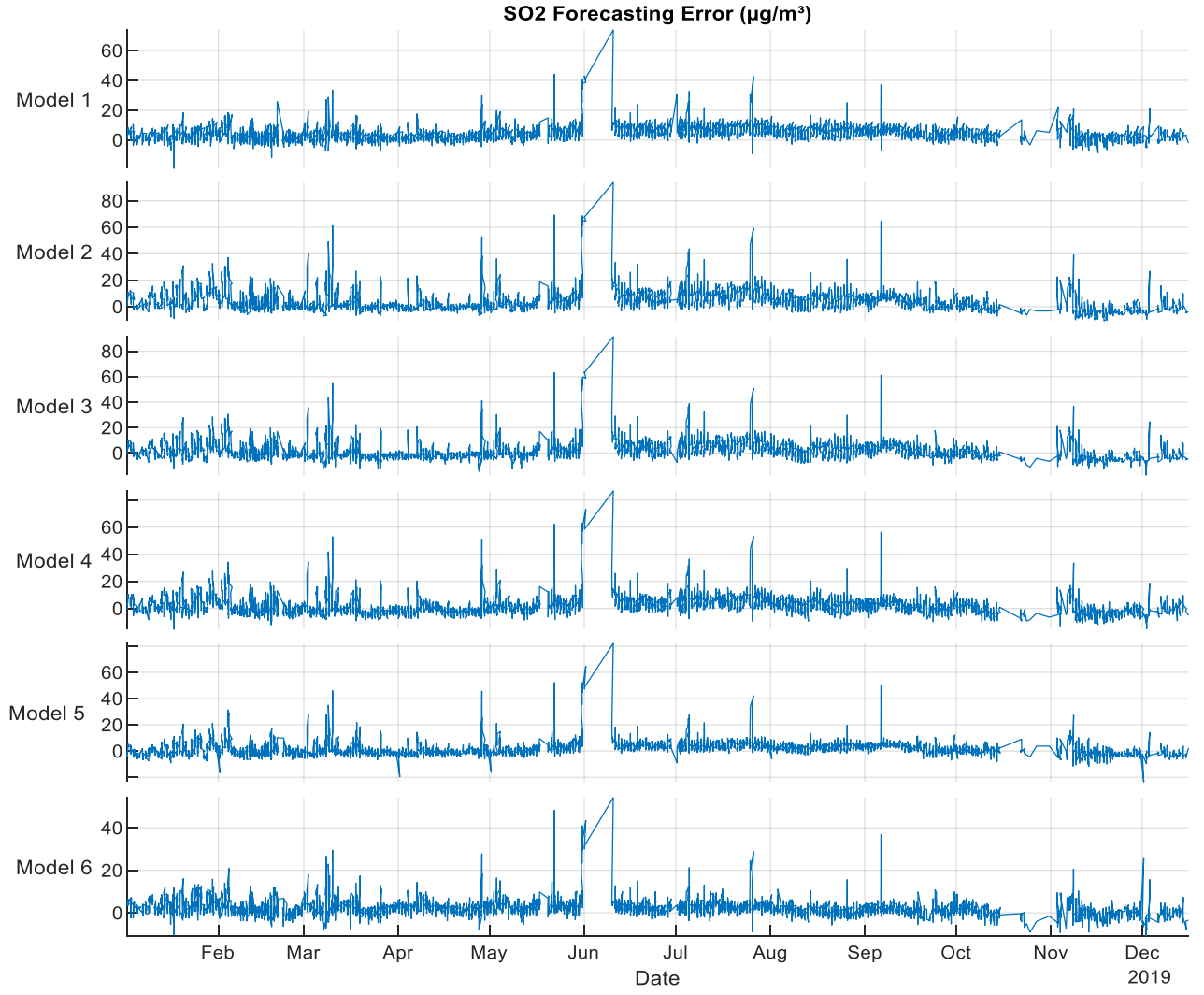

Figure 9: $\mathrm{SO}_{2}$ error $\left(\mu \mathrm{g} / \mathrm{m}^{3}\right)$ forecasting errors for 2019 using NARX. 


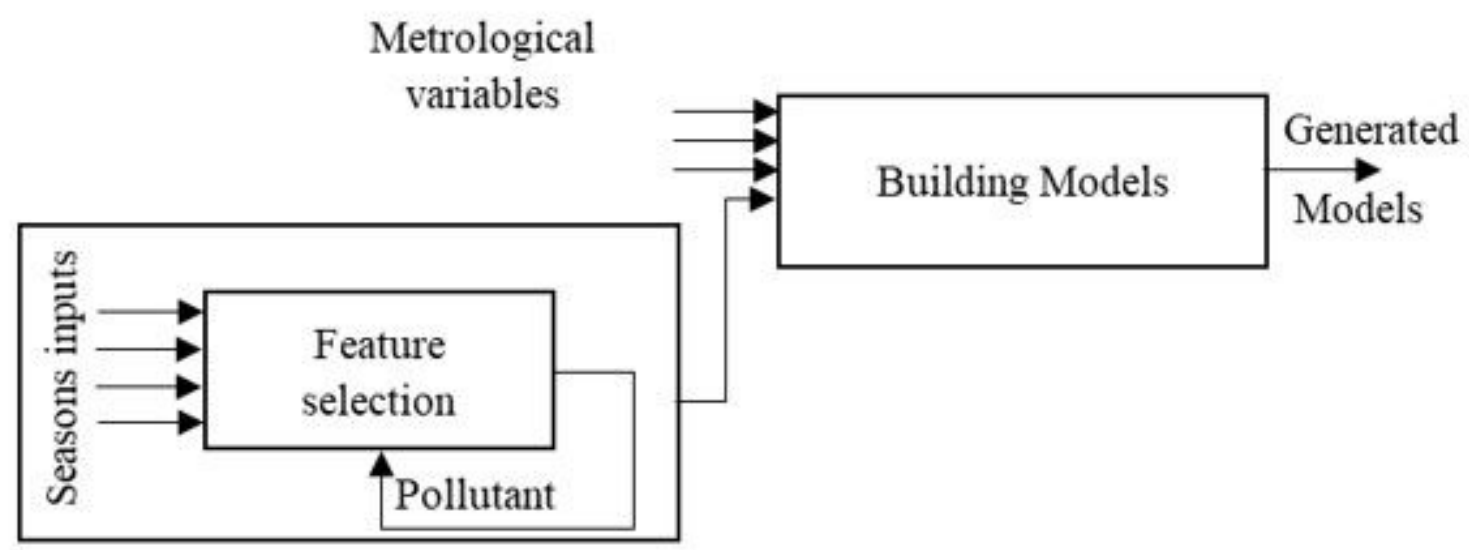

Figure 1

The created models' methodology

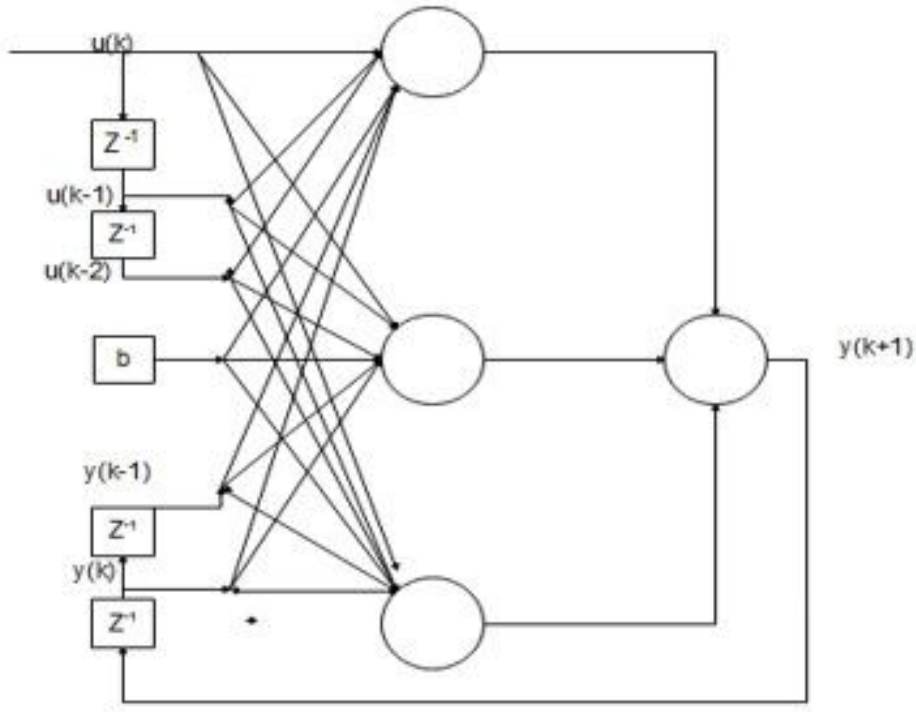

\section{Figure 2}

NARX model with tapped delay line at input. To sum up all the used methodology in this study a flow chart in Figure 3 is considered. 


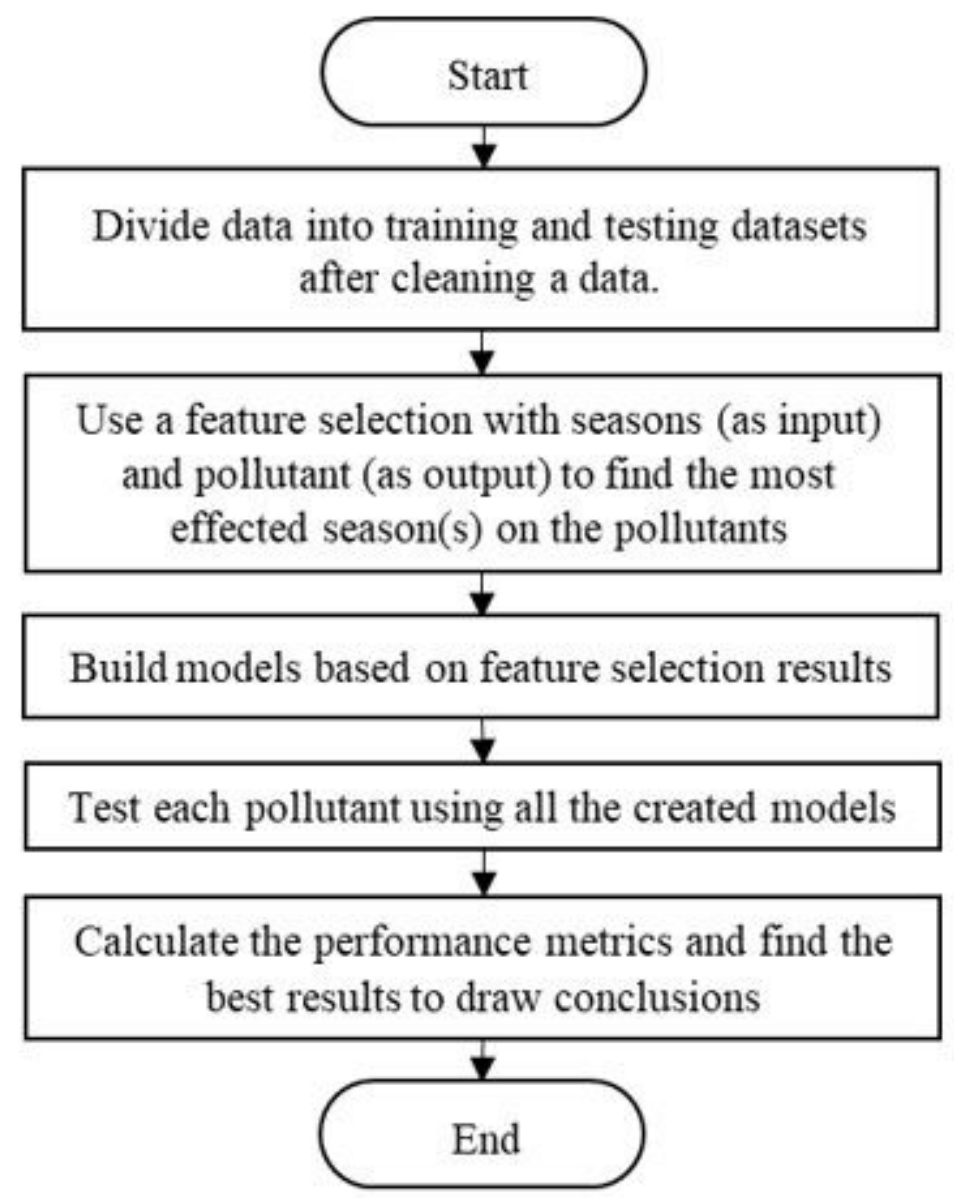

\section{Figure 3}

The used methodology to build models. 

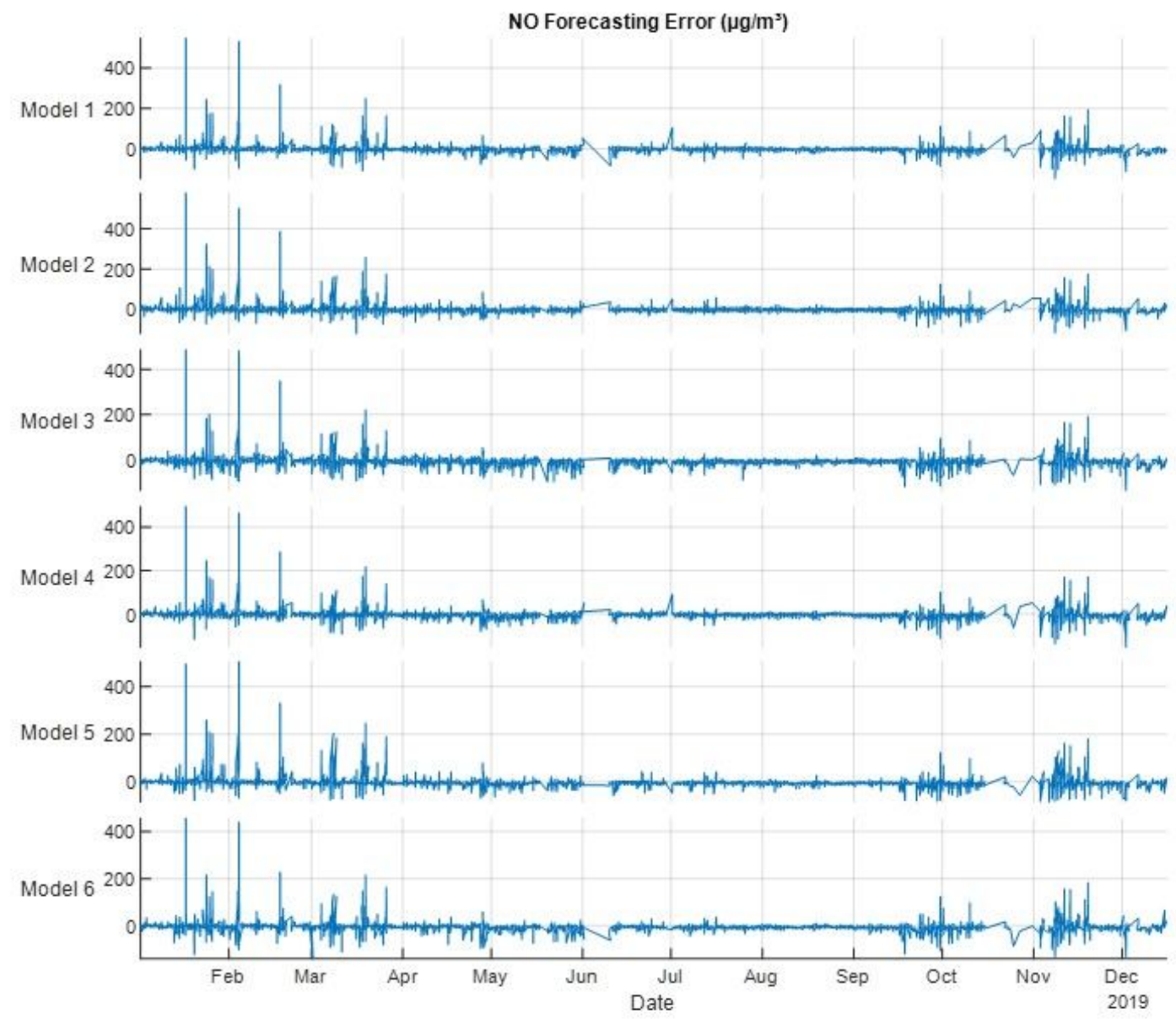

Figure 4

NO error $\left(\mu \mathrm{g} / \mathrm{m}^{3}\right)$ forecasting for 2019 using NARX. 


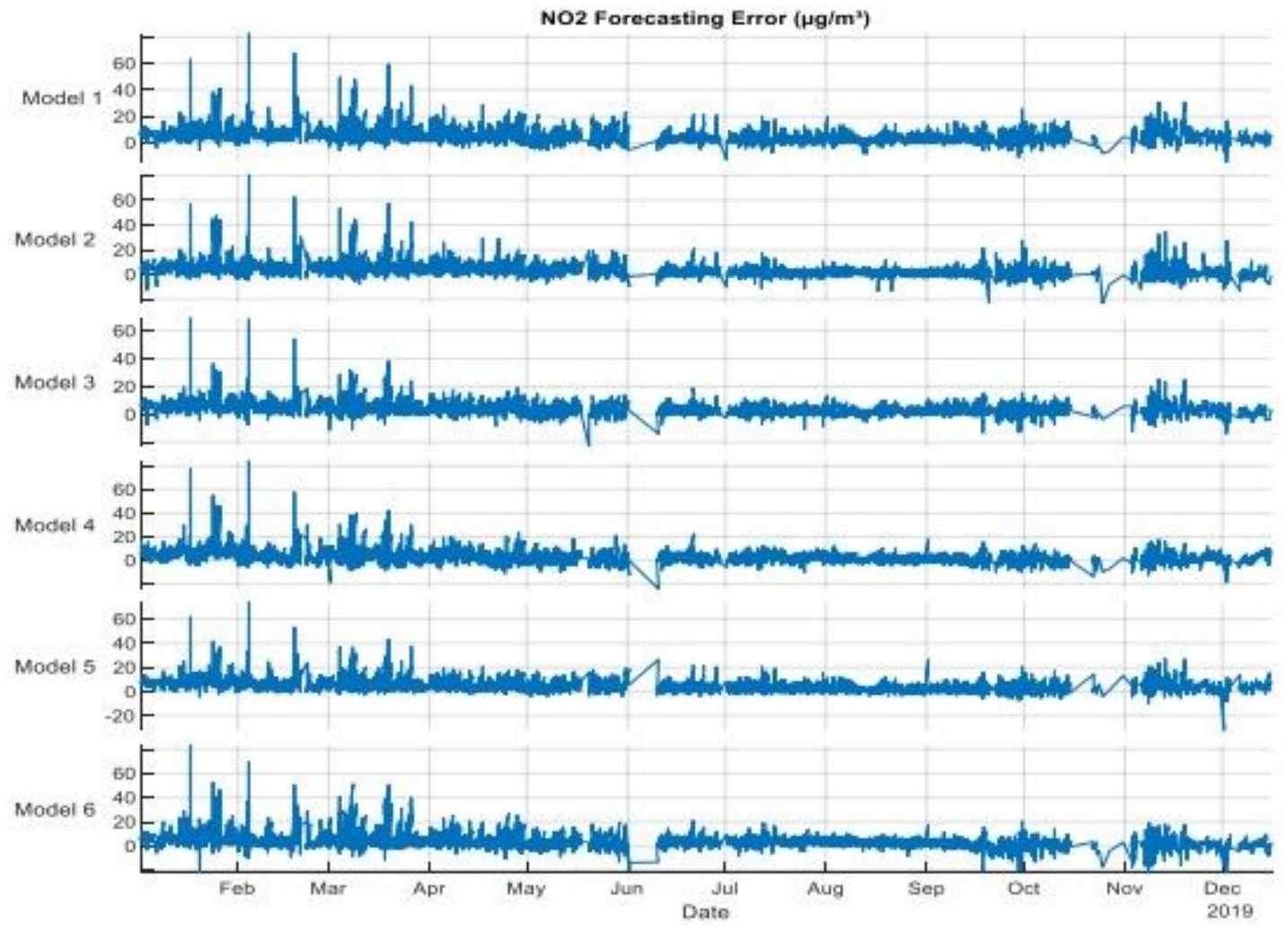

Figure 5

NO2 error $\left(\mu \mathrm{g} / \mathrm{m}^{3}\right)$ forecasting for 2019 using NARX. 


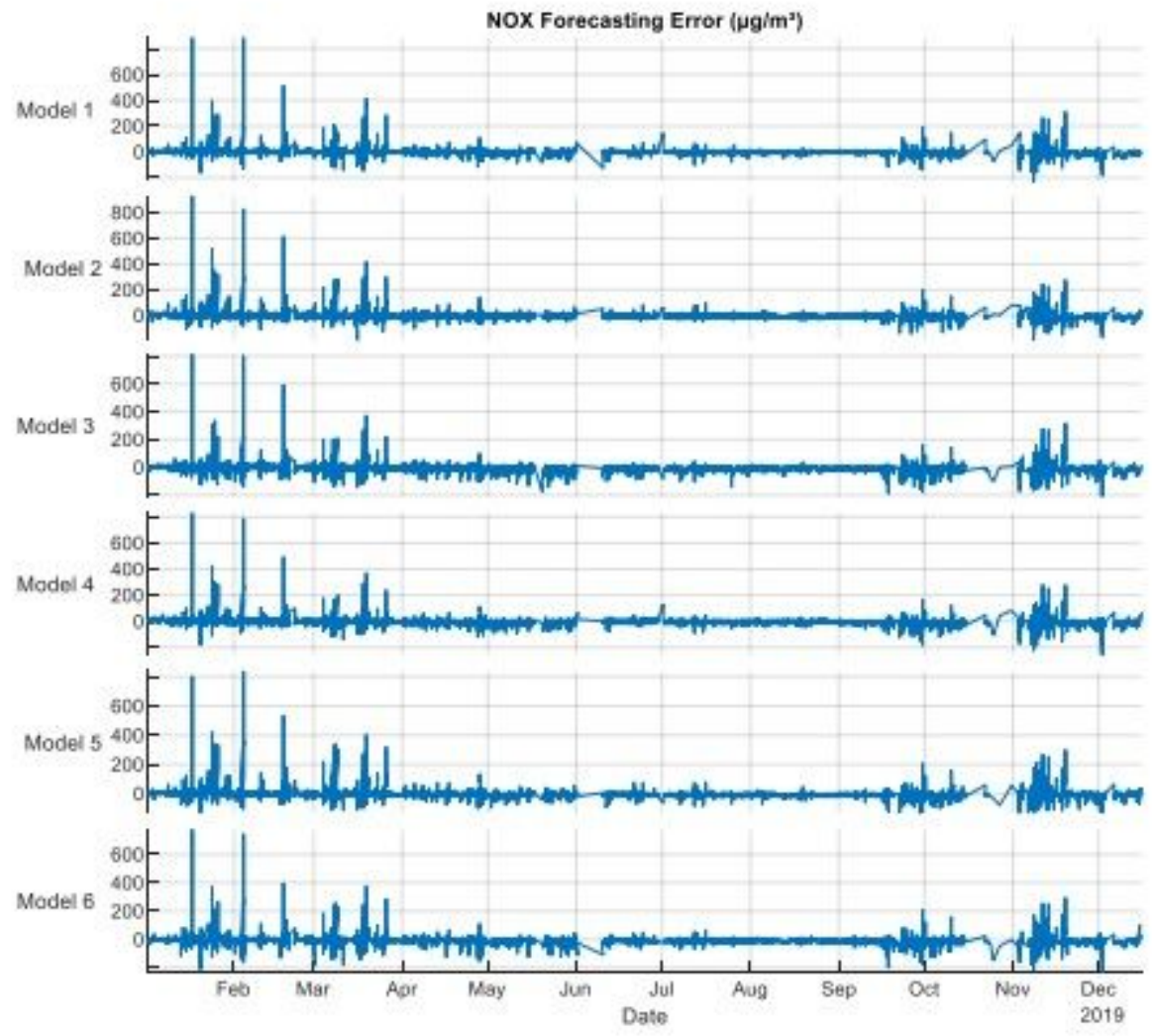

Figure 6

NOX error $\left(\mu \mathrm{g} / \mathrm{m}^{3}\right)$ forecasting errors for 2019 using NARX. 

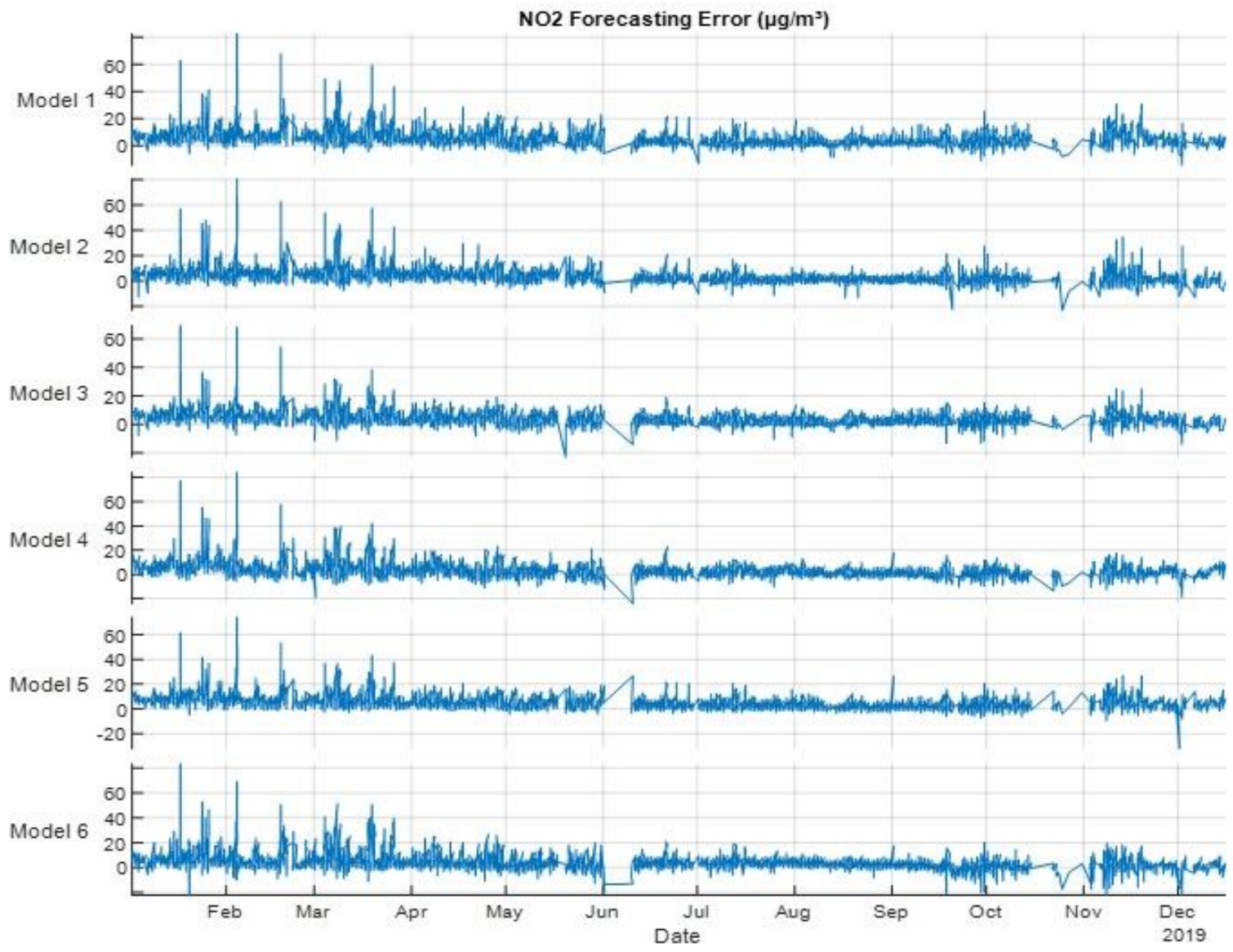

Figure 7

NO2 error $\left(\mu \mathrm{g} / \mathrm{m}^{3}\right)$ forecasting for 2019 using NARX. 

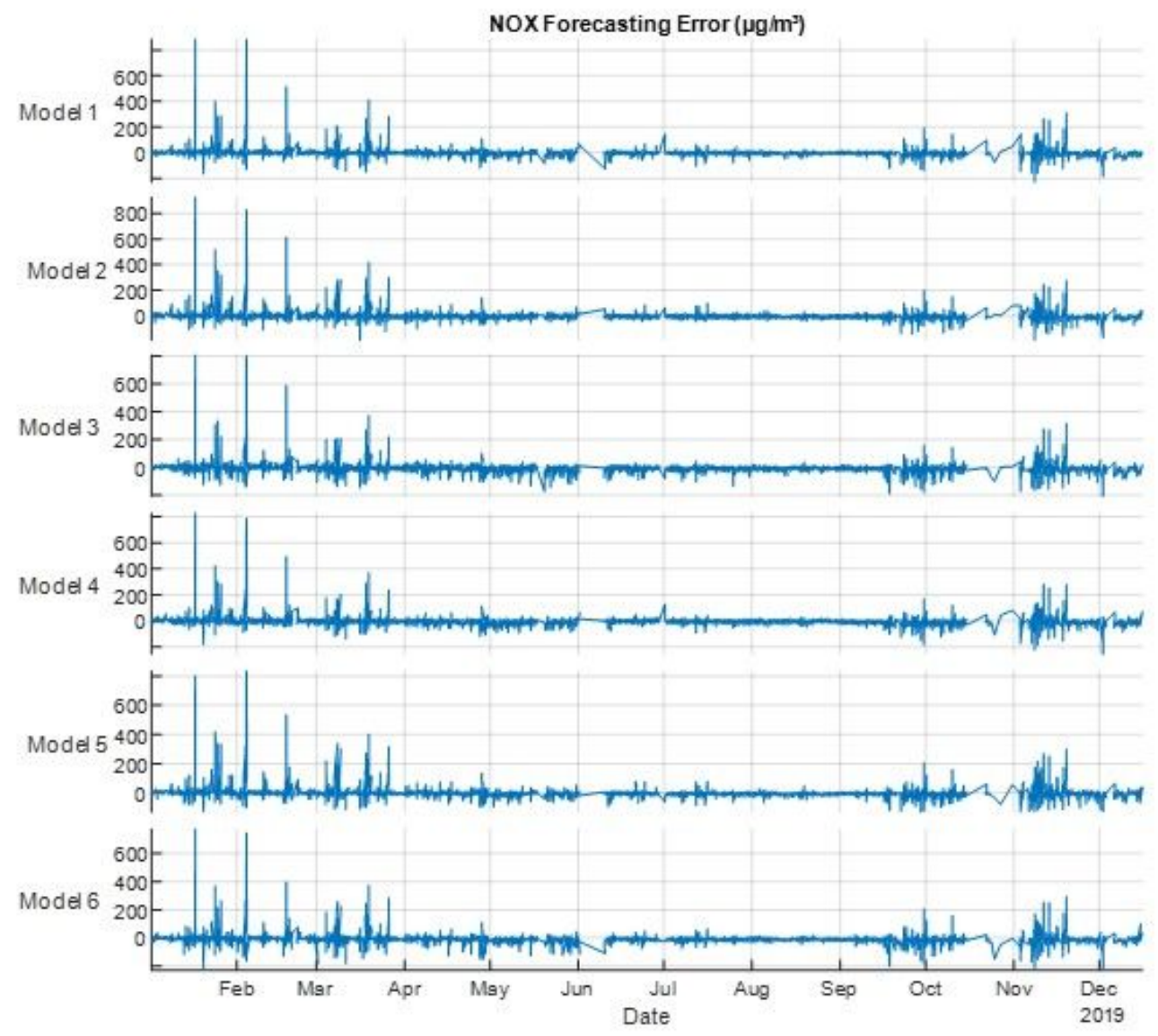

\section{Figure 8}

NOX error $\left(\mu \mathrm{g} / \mathrm{m}^{3}\right)$ forecasting errors for 2019 using NARX. 


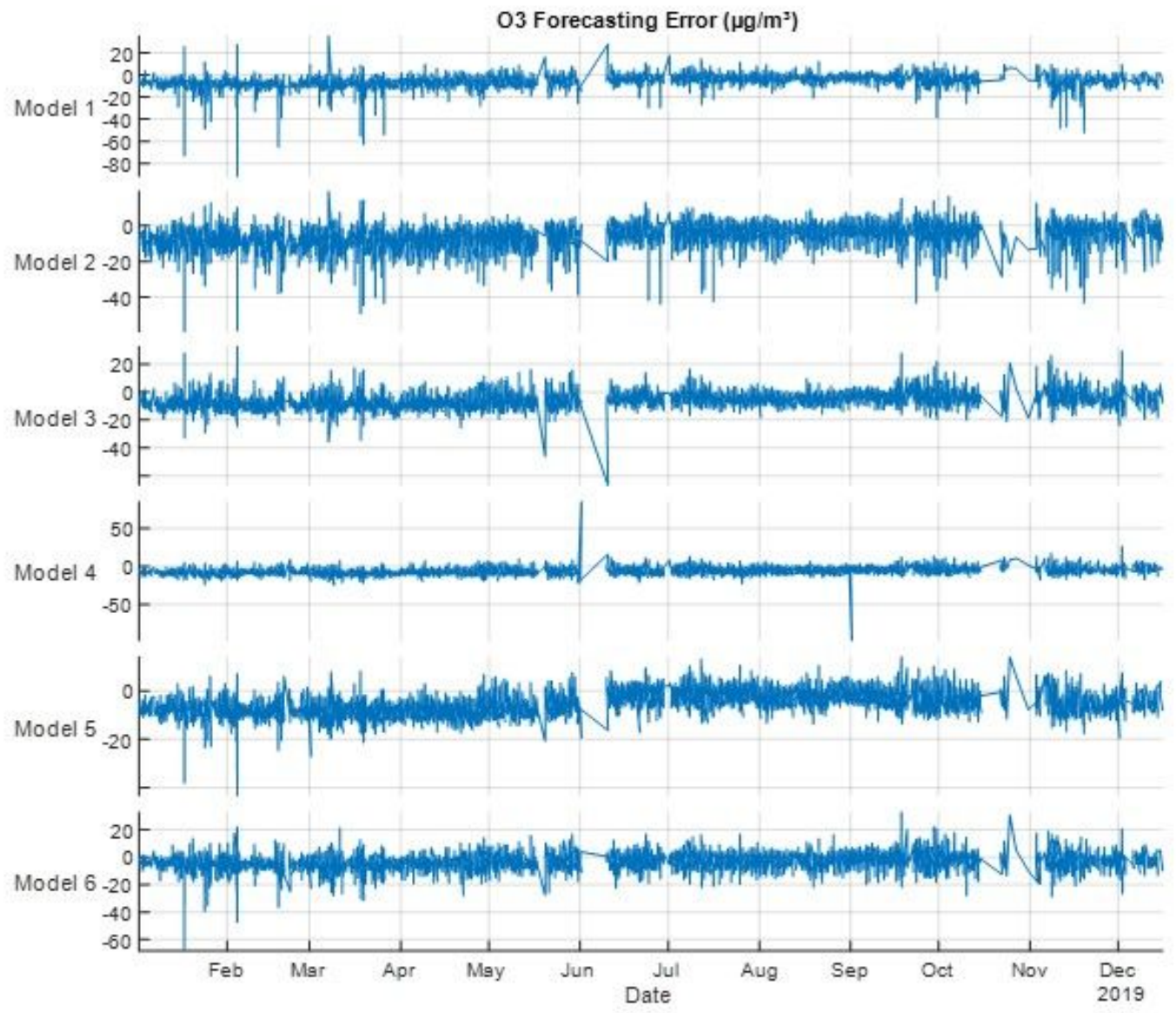

Figure 9

O3 error $\left(\mu \mathrm{g} / \mathrm{m}^{3}\right)$ forecasting errors for 2019 using NARX. 


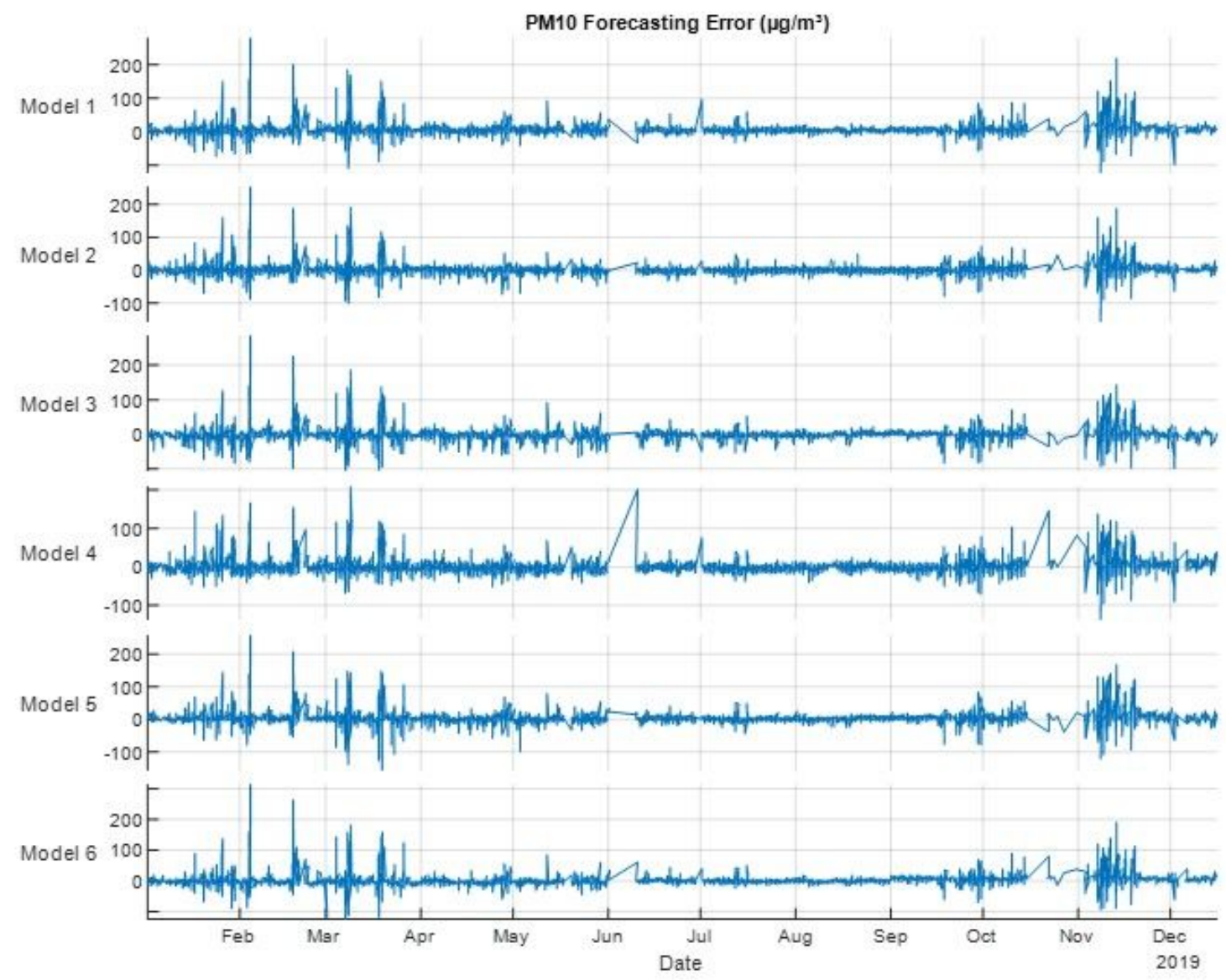

Figure 10

PM10 error $\left(\mu \mathrm{g} / \mathrm{m}^{3}\right)$ forecasting errors for 2019 using NARX. 

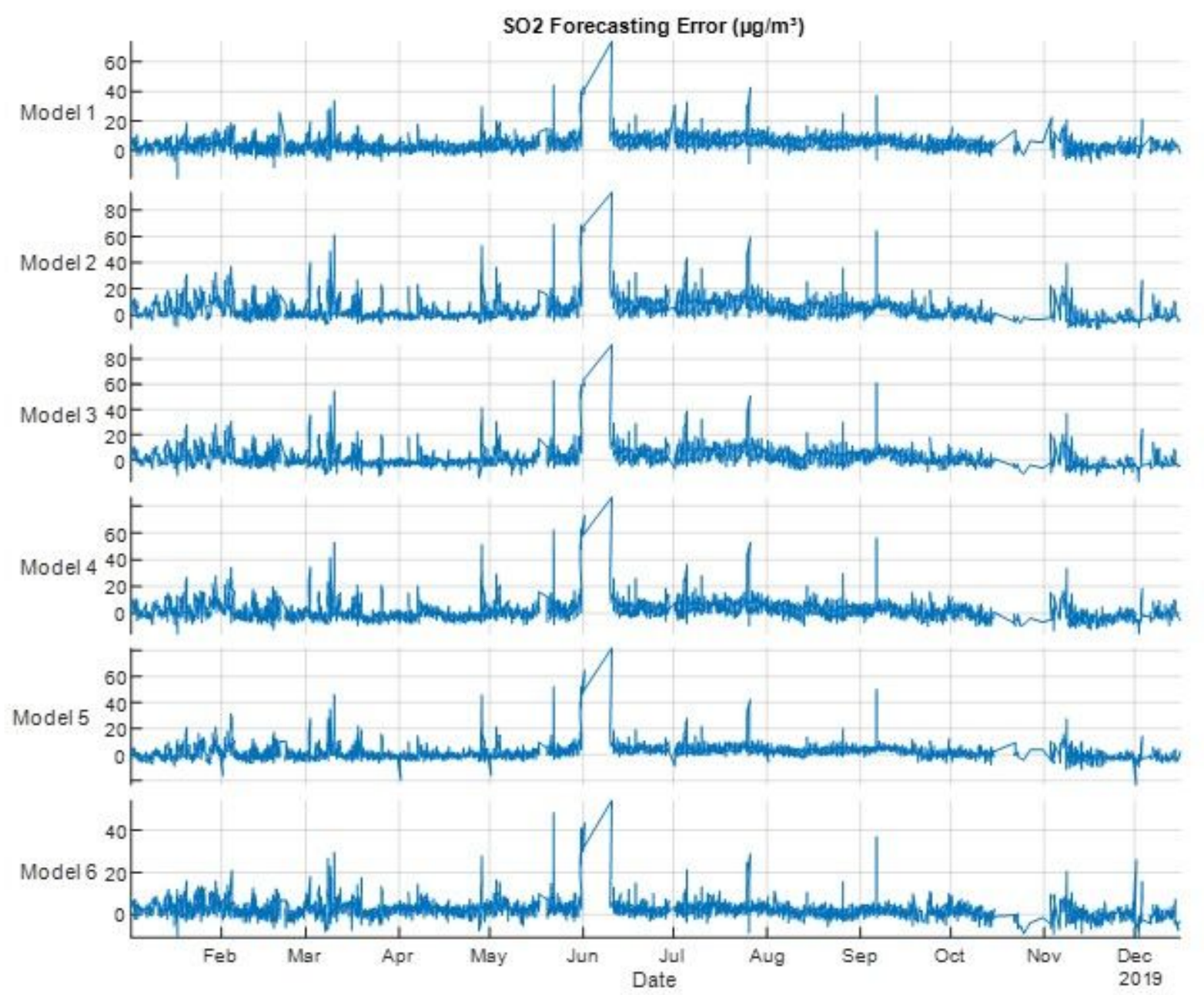

Figure 11

SO2 error $\left(\mu \mathrm{g} / \mathrm{m}^{3}\right)$ forecasting errors for 2019 using NARX. 